\title{
JOURNAL OF BIOENGINEERING AND TECHNOLOGY APPLIED TO HEALTH
}

An Official Publication of the Health Institute of Technology - ITS/SENAI CIMATEC

EDITOR-IN-CHIEF

Leone Peter Andrade

PUBLISHED BY SENAI CIMATEC

SENAI
CIMATEC
SISTEMA

June 2019

Printed in Brazil 


\section{JOURNAL OF BIOENGINEERING AND TECHNOLOGY APPLIED TO HEALTH}

An Official Publication of the Health Institute of Technology - ITS/SENAI CIMATEC

\section{EDITOR-IN-CHIEF}

Leone Peter Andrade

\section{DEPUTY EDITOR}

Roberto Badaró

\section{ASSISTANT DEPUTY EDITORS}

Alex Álisson Bandeira Santos (BR)

Lilian Lefol Nani Guarieiro (BR)

Valéria Loureiro (BR)

\section{ASSOCIATE EDITORS}

Alan Grodzinsky (US)

Bruna Aparecida Souza Machado (BR)

Carlos Coimbra (US)

Eduardo Mario Dias (BR)

Luiz Erlon Araújo Rodrigues (BR)

Frank Kirchner (DE)

Jorge Almeida Guimarães (BR)

Josiane Dantas Viana Barbosa (BR)

Milena Soares (BR)

Preston Mason (US)

Sanjay Singh (US)

Steven Reed (US)

Valter Estevão Beal (BR)
STATISTICAL ASSOCIATE EDITOR

Valter de Senna (BR)

\section{EDITORIAL BOARD}

Carlos Augusto Grabois Gadelha (BR)

Corey Casper (US)

Erick Giovani Sperandio Nascimento (BR)

George Tynan (US)

Hercules Pereira (BR)

Hermano Krebs (US)

Immanuel Lerner (IR)

Jailson Bittencourt de Andrade (BR)

James Chong (KR)

José Elias Matieli (BR)

Maria Lídia Rebello Pinho Dias (BR)

Mario de Seixas Rocha (BR)

Regina de Jesus Santos (BR)

Roberto de Pinho (BR)

Sanjay Mehta (US)

Vidal Augusto Zapparoli Castro Melo (BR)

Vilson Rosa de Almeida (BR)

\section{PRODUCTION STAFF}

Luciana Knop, Managing Editor

Valdir Barbosa, Submissions Manager

Flavia Carvalho, Secretary 


\section{JOURNAL OF BIOENGINEERING AND TECHNOLOGY APPLIED TO HEALTH}

Volume 2 ・ Number 2

June 2019

\section{Original Papers}

Detection of Impurities in Anti-infective Generic Drugs in Brazil by Liquid Chromatography-Mass Spectrometry 36

Jeancarlo Pereira dos Anjos, Samuel Sherratt, Josiane Dantas, Valdir Gomes Barbosa Junior, R. Preston Manson, Roberto Badaro

Lethal Ovitrap CIMATEC: A New Trap for Arbovirus Transmitting Mosquitoes

Eduardo Oyama, Daniel Mota

\section{Brief Communications}

Identification of Sex Using Linear Skull Measures: The Importance of Imaging in Biotechnology 54

Alile Carmo, Ana Carolina Mariz, Leandro Santos, Marianna Torres, Raí Santos, Roberto Monteiro

\section{Review Articles}

Liposome Drug Delivery in Cancer Chemotherapy: Review and Multifactorial Analysis. .59

Tatiara Régis, Luciana Knop, Bruna Machado, Valter de Senna

\section{Health Innovation Innitiatives}

The Management of Electro-Medical Equipment in Intensive Care Units: Assurance of Traceability and Metrological Reliability . .70

Juliana Lins de Oliveira, Herman Augusto Lepikson

\section{Case Report}

Osteoma: A Case Report Based on Image Technology .75

Alile Carmo, Ana Carolina Mariz, Leandro Santos, Marianna Torres, Raí Santos, Roberto Monteiro

\section{Instructions for Authors}

Statement of Editorial Policy

Checklist for Submitted Manuscripts 
The Journal of Bioengineering and Technology Applied to Health (JBTH) is an official publication of the Health Institute of Technology - ITS/SENAI CIMATEC. It is published quarterly (March - June - September - December) in English by SENAI CIMATEC - Avenida Orlando Gomes, 1845, Piatã, Zip Code: 41650-010, Salvador-BahiaBrazil; phone: (55 71) 3879-5501. The editorial offices are at Health Institute of Technology (ITS) - SENAI CIMATEC.

\section{Editorial Office}

Correspondence concerning subscriptions, advertisements, claims for missing issues, changes of address, and communications to the editors should be addressed to the Deputy Editor, Dr. Roberto Badaró, Journal of Bioengineering and Technology Applied to Health - JBTH - Avenida Orlando Gomes, 1845, Piatã, Zip code: 41650-010, Salvador-Bahia-Brazil; phone: (55 71) 3879-5501; or sent by e-mail: jbth@jbthonline.com

\section{Permissions}

Journal of Bioengineering and Technology Applied to Health and Health Institute of Technology - ITS/SENAI CIMATEC. All rights reserved. Except as authorized in the accompanying statement, no part of the JBTH may be reproduced in any form or by any electronic or mechanic means, including information storage and retrieval systems, without

COVER: Culture of adipose tissue mesenchymal cells. Image courtesy of Dr. Ricardo Ribeiro. All rights reserved. the publisher's written permission. Authorization to photocopy items for internal or personal use, or the internal or personal use by specific clients is granted by the Journal of Bioengineering and Technology Applied to Health and SENAI CIMATEC for libraries and other users. This authorization does not extend to other kinds of copying such as copying for general distribution, for advertising or promotional purposes, for creating new collective works, or for resale.

\section{Postmaster}

Send address changes to JBTH, Avenida Orlando Gomes, 1845, Piatã, Zip Code: 41650-010, Salvador-Bahia-Brazil.

\section{Information by JBTH-ITS/SENAI CIMATEC}

Home-page: www.jbthonline.com

E-mail: jbth@jbthonline.com

Phone: (55 71) 3879-5501 / 3462-9599.

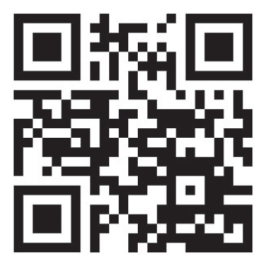

\section{Copyright}

(C) 2019 by Journal of Bioengineering and Technology Applied to Health ITS/SENAI CIMATEC All rights reserved. 


\section{SIINTEC witensarona LSMmossum on INNOVATION AND TECHNOLOGY}

SIMPÓSIO INTERNACIONAL DE INOVAÇÃO E TECNOLOGIA

\begin{tabular}{l|l} 
CIRCULAR ECONOMY & ECONOMIA CIRCULAR
\end{tabular}

The International Symposium on Innovation and Technology (SIINTEC) happens since 2015. The annual event is promoted by SENAI CIMATEC. The objective of the event is to contribute significantly to the scientific and technological development in Brazil, seeking the massive participation between academy and industry involved in research, development and innovation.

The V SIINTEC will be held from October 09-11, 2019, and has the theme: "Circular Economy". The event will give opportunity to discuss the main topics related to technological innovations as basis for meeting the challenges of productive processes.

The event has an annual publication of complete works with registration by the Brazilian Institute of Information in Science and Technology (IBICTI). Through this yearbook of published papers, it is possible to measure the impact and interest of the scientific community in the dissemination of the researches that has been developed in Brazil and around the World. Three yearbooks will have specific sessions for publication: Modeling and Industrial Technology, Management and Industrial Technology, Engineering, SENAI Institute of Innovation and Sustainable Development.

DATE OF EVENT

PAPER SUBMISSION DEADLINE

FINAL PAPER SUBMISSION DEADLINE

RESULT OF THE APPROVED PAPERS 


\title{
Detection of Impurities in Anti-infective Generic Drugs in Brazil by Liquid Chromatography-Mass Spectrometry
}

\author{
Jeancarlo Pereira dos Anjos*1, PhD; Samuel Sherratt ${ }^{2}$ Bsc, PhD; Josiane Dantas ${ }^{1}$ PhD; Valdir Gomes Barbosa \\ Junior'; R. Preston Manson ${ }^{2,3}$; Roberto Badaro', MD, PhD \\ ${ }^{1}$ Health Institute of Technology - SENAI CIMATEC, National Service of Industrial Learning - SENAI; Salvador, Bahia, \\ Brazil; ${ }^{2}$ Elucida Research, Beverly, Massachusetts, USA; ${ }^{3}$ Brigham \& Women's Hospital, Harvard Medical School, Boston, \\ Massachusetts, USA
}

\begin{abstract}
Impurities found in generic medicinesmay contribute to loss of efficacy and adverse side effects when administered to patients suffering from various diseases. Methods of analysis of the quality of drug products are well advanced. Herein, we used Liquid Chromatography with Diode Array Detector coupled to Mass Spectrometry to detect the presence of organic impurities and determine the quantity of the Active Pharmaceutical Ingredient (API) present in representative Antibiotics (2) and Antifungals (2). Possible impurities were detected in some of the generic drugs in both classes of anti-infective drugs. No impurities were detected in the amoxicillin. The compounds 3'-N,N-Di(demethyl) azithromycin (azithromycin impurity $\mathbf{E}$ ) and 3'-De(dimethylamino)-3'-keto azithromycin (azithromycin impurity $\mathbf{N}$ ) were detected in generic azithromycin. For itraconazole, the compounds cis-[2-(2,4-dichlorophenyl)-2-(1H-1,2,4-triazol4-yl-methyl)-1,3-dioxolan-4-yl]methylmethanesulfonate and trans-[2-(2,4-dichlorophenyl)-2-(1H-1,2,4triazol-1-yl-methyl)-1,3-dioxolan-4-yl]methylmethanesulfonate, besides a third substance identified as 2(2-Butyl) -4-\{4-[4-(4-methyloxy-phenyl)-piperazin-1-yl]-phenyl\}-2,4-dihydro-[1,2,4]-triazol-3-one were detected as possible impurities. Interestingly, an additional peak was noted in the chromatogram for the generic fluconazole, in addition to the peak of the API; however, none of known impurities of fluconazole were identified. We conclude that tests in addition to bioequivalence measurements may be required to assess post-market generic quality. Such surveillance of generic quality should be performed routinely. Keywords: Generic Drugs. Mass Spectrometry. Drug Impurities.
\end{abstract}

Impurities may be present in medicinal products generated from poorly controlled manufacturing conditions,poor-quality substrates and/or API synthesized by a process different from than the certified synthesis pathway $[1,2]$. The impact of the use of low-quality drugs is related to the adverse effects caused by the presence of undesirable substances, such as impurities and worse, it may contain theincorrect Active Pharmaceutical Ingredient (API) [3].

The adulteration of drugs has been grouped into five categories: (i) copies of the authentic medicine, butwith changes in the quantityof API; (ii) products with incorrect API, which may be of Received on 20 March 2019; revised 22 May 2019.

Address for correspondence: Dr. Jeancarlo Pereira dos Anjos. Avenida Orlando Gomes, N. 1845, Piatã. Zip Code: 41650010. Salvador, Bahia, Brazil. Phone: (+55 71) 3879-5501.Email: jeancarlo.anjos@fieb.org.br. This work was funded from SENAI-CIMATEC Research Center, Bahia, Brazil and the Minister of Health of Brazil.

J Bioeng. Biotech. Appl. Health 2019;2(2):36-46.

(C) 2019 by SENAI CIMATEC. All rights reserved. inferiorquality; (iii) preparations with an absence of API; (iv) medicines with very high or very low API content; (v) contamination with known and/ or unknown impurities [4,5].

Due to lower costs, the use of generic drugs has been promotedin many countries [6]. Policies to reduce costs and increase the availability of medicineshave contributed to the preventionofdrug shortages, in addition to improving accessibility to drugs invarious therapeutic classes, especially in developing countries [7-9]. Analytical methods for rapid and accurate drug testingare necessary to combat the increasing number of adulterated drugs as well assophisticated counterfeits [10-15]. The deployment of such analytical technology will have an important role indetecting drug tampering. The safety of medicines depends on the absenceof impurities and accurate API levels. Effective and reproduciblemethods fordetecting drug impurities and API levels may provide insightsinto the quality of generic drugs available in the global marketplace [16,17]. 
High-performance liquid chromatography (HPLC) has been a common technique for the determination of impurities in pharmaceutical products [11]. For basic identification and quantification of the components of the sample, $\mathrm{UV} / \mathrm{Vis}$ spectrophotometry data is gathered using a diode array detector (DAD). Additionally, this analytical technique can be coupled to mass spectrometry (MS) for the structural identification of components of interest such as impurities resulting from improper synthesis $[18,19]$. Thus, chromatographic techniques have been powerful tools in the analysis and characterization of adulterated medicines because they assess the composition of the analyzed sample [10].

Herein we analyzed the generic antibiotics amoxicillin trihydrate, azithromycin dihydrate, and the generics antifungals fluconazole and itraconazole by high-performance liquid chromatography to detect the presence of impurities in the products.

Generic drugs were provided by the Minister of Health of Brazil (MH). The generic medicines provided were selected from batches stored at the $\mathrm{MH}$ that were ready to be distributed to the population. Each generic and branded drug tablet or capsule was prepared for HPLC-DAD-MS analysis by extracting API in methanol, with the exception of amoxicillin trihydrate (in water). The analyses were tested in collaboration with other laboratories at a referral laboratory in Boston, MA - USA (personal communication from Elucida Research). Certified standards of the API for the antibiotics (amoxicillin trihydrate and azithromycin dihydrate), were purchased from Toronto Research Chemicals (Toronto, Canada) for comparative analysis.

API Impurity and Quantification Analysis were performed as follows: Stock solutions were prepared at 1-5 mg mL-1 in an aqueous or organic solvent to match the corresponding sample preparation for each compound. Analytical curves for each compound were constructed at the following concentrations: $0.05,0.1,0.2,0.25$ and $0.5 \mathrm{mg} \mathrm{mL}-1$.

Tablets were crushed using an Agate mortar and pestle and solubilized in an aqueous or organic solvent at $1-5 \mathrm{mg} \mathrm{mL}-1$, depending on the nature of the API. For products delivered in gelatin capsule form, the two halves of the capsule were separated and the contents were solubilized in aqueous or organic solvent. Solutions were stirred at least 4 hours to ensure uniform distribution of material. The active pharmaceutical ingredient (API) was then separated from insoluble excipient by centrifugation at room temperature for 30 minutes. The supernatant (containing the API) was then removed and stored at $4^{\circ} \mathrm{C}$ before HPLCDAD-MS analysis.

Each sample was diluted down to a nominal concentration of 0.2 or $0.5 \mathrm{mg} \mathrm{mL}-1$, and then the actual concentration was determined based on the analytical curve. Results were reported as a percentage of expected concentration compared to standard solutions as well as compared to branded formulations when applicable. For impurity analysis, samples were run at $0.5 \mathrm{mg} \mathrm{mL}-1$.

Samples and standard solutions were run on an Agilent 1260 Series LC, equipped with a diode array detector (DAD) and an Agilent 6120B MSD for mass spectrometry analysis. All samples were run on a Poroshell 120 EC-C18 4.6 X $100 \mathrm{~mm}$ $2.7 \mu \mathrm{M}$ column. For the evaluation of impurities, the drug samples were analyzed using the mass spectrometric detector, described above, in SCAN mode $(\mathrm{m} / \mathrm{z} 100$ to 800$)$. For the quantification of the APIs, the diode array detector (DAD) was operated at the wave lengths according to the optimal absorbance of electromagnetic radiation for each analyte.

Figure 1A shows the chromatograms and mass spectrum for the pure azithromycin dihydrate standard. In Figure 1A, the peak at $4.797 \mathrm{~min}$ corresponds to azithromycin, as evidenced by the characteristic mass spectrum and associated molecular weights (Figure 1B). The molecular weight of azithromycin is $749 \mathrm{~g}$ mol- 1 .

Figure 2A shows the LC-MS analysis, where the peak at $4.832 \mathrm{~min}$ corresponds to generic azithromycin while the 6.052 min peak corresponds to a potential impurity not seen in the standard formulation. In Figure 2B, we show the mass spectrum analysis of this peak, which 
Figure 1. Chromatogram obtained by LC-MS (SCAN mode) for pure azithromycin dihydrate (A) and mass spectrum of pure azithromycin dihydrate (B).
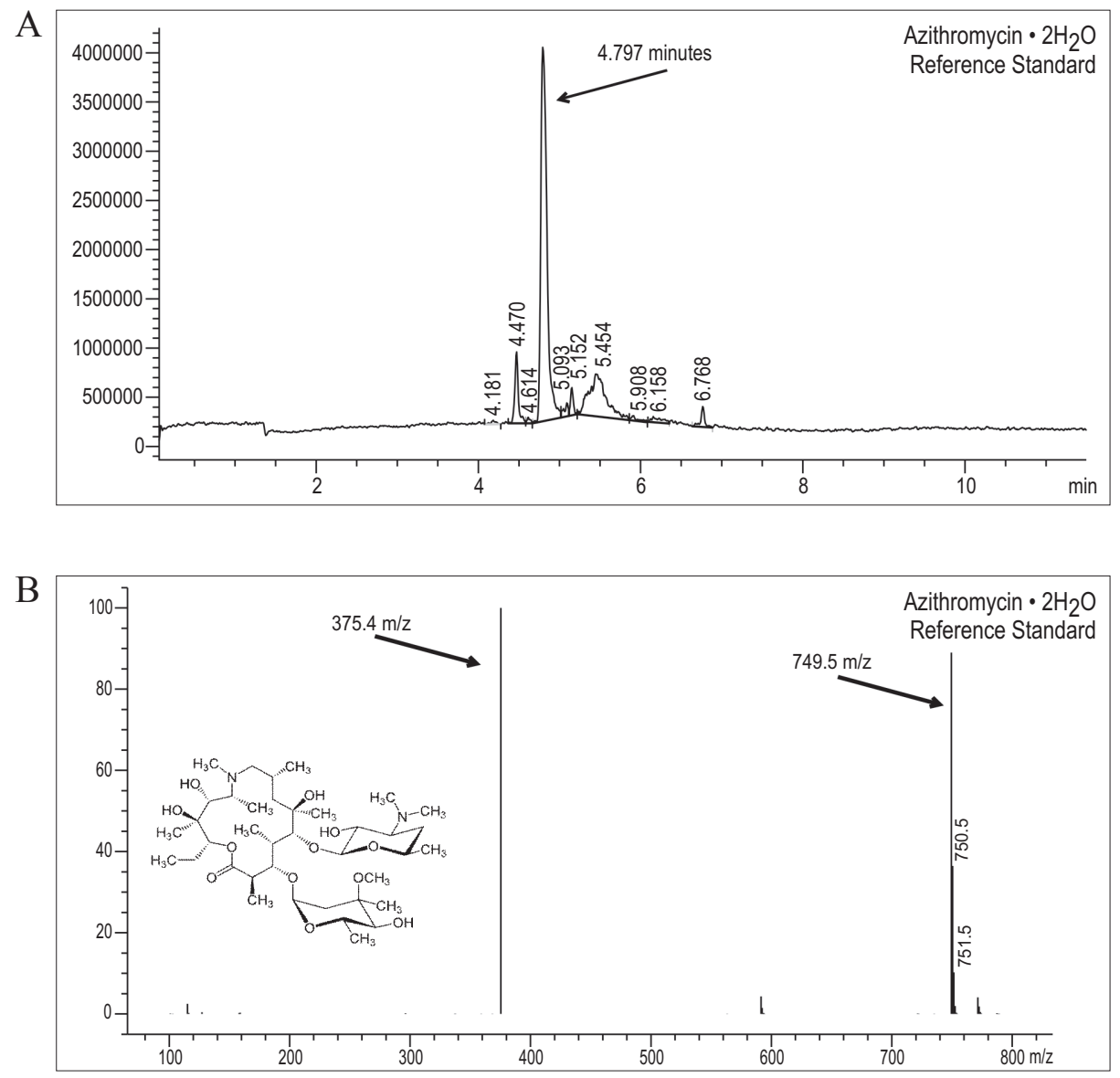

revealed the characteristic of the mass-to-charge ratio associated with azithromycin, which also matches the pattern of the standard azithromycin. The molecular weight of azithromycin is $749 \mathrm{~g}$ mol-1, as shown in Figure 2B. Also, in Figure 2A, we noted several smaller peaks, which were also seen in the standard formulation.

The peak seen at 6.052 min (Figure 2A) did not have a corresponding peak in the standard formulation. Analysis of the mass spectrum of this peak (Figure 3) revealed a chemical entity with a molecular weight around to $720 \mathrm{~g}$ mol-1. According to Chang et al. (2015) (20), there are two possible impurities in the azithromycin with similar molecular weight. One of the molecules, azithromycin EP impurity E (3'-N,N-Di(demethyl) azithromycin), has a molecular weight of $720.9 \mathrm{~g}$ mol-1 (Figure 4A).Anothermolecule, azithromycin EP impurity N (3'-De(dimethylamino)-3'-keto azithromycin), has a molecule weight of $719.9 \mathrm{~g}$ mol-1 (Figure 4B).

The reference and generic formulations of amoxicillin hydrated were analyzed for impurities using LC-MS as previously described. The amoxicillin trihydrate standard (2.992 $\mathrm{min})$ and both the reference $(2.985 \mathrm{~min})$ and generic $(2.982$ min) amoxicillin trihydrate show a similar peak as shown in Figure 5. The mass spectrum of the standard, the reference and the generic confirmed that the only peak observed in both chromatograms correspond to amoxicillin hydrated. Nevertheless, no other peaks were noted. Thus, it confirms that no impurities were encountered in both reference and generic amoxicillin. 
Figure 2. Chromatogram obtained by LC-MS (SCAN mode) for generic azithromycin dihydrate (A) and the mass spectrum of 4.832 min peak for generic azithromycin dihydrate (B)
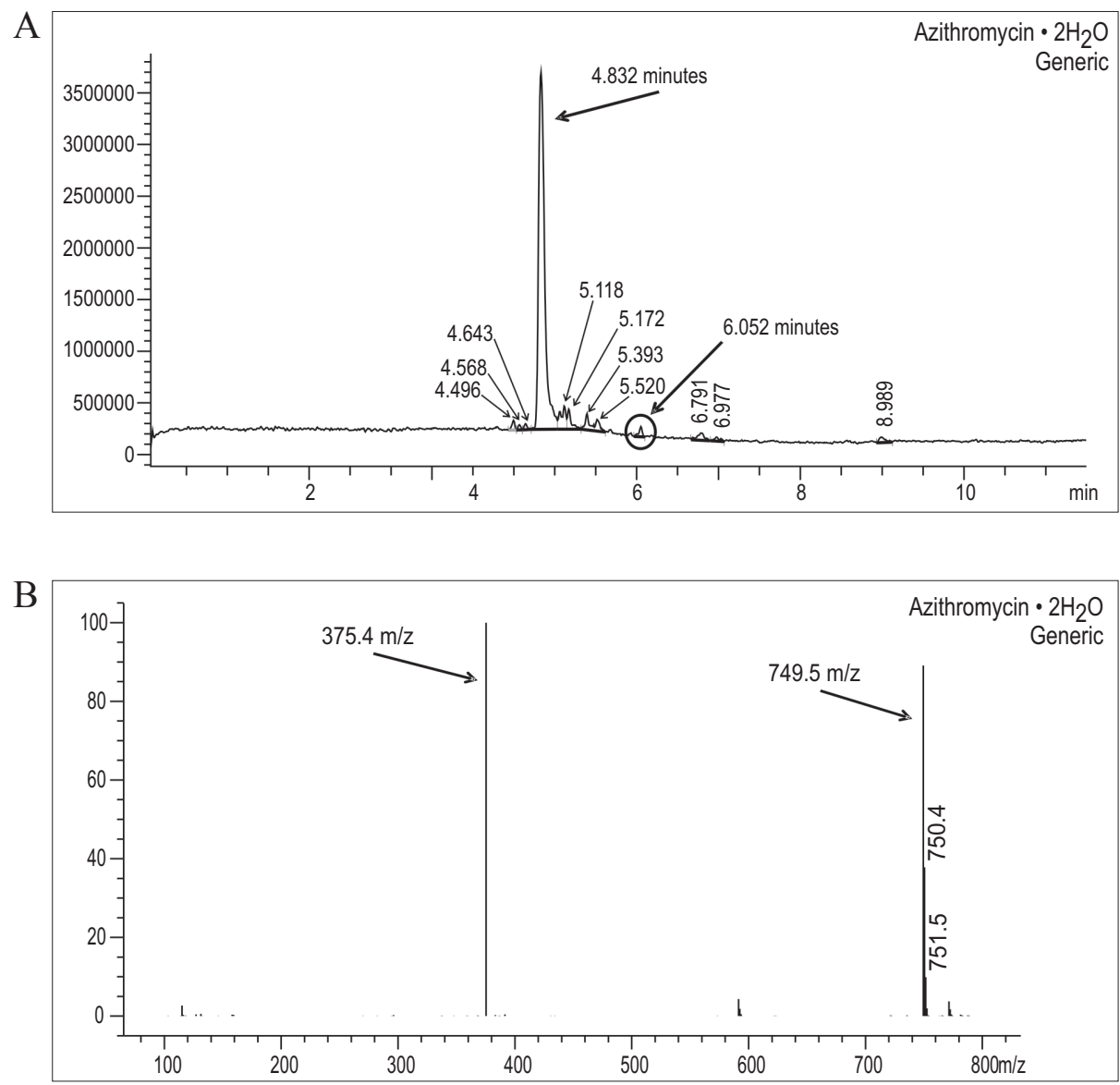

Figure 3. Mass spectrum of 6.052 min peak for generic azithromycin dihydrate. The pattern of this mass spectrum indicates a chemical entity with a molecular weight around $720 \mathrm{~g}$ mol-1 that was not seen in the standard formulation.

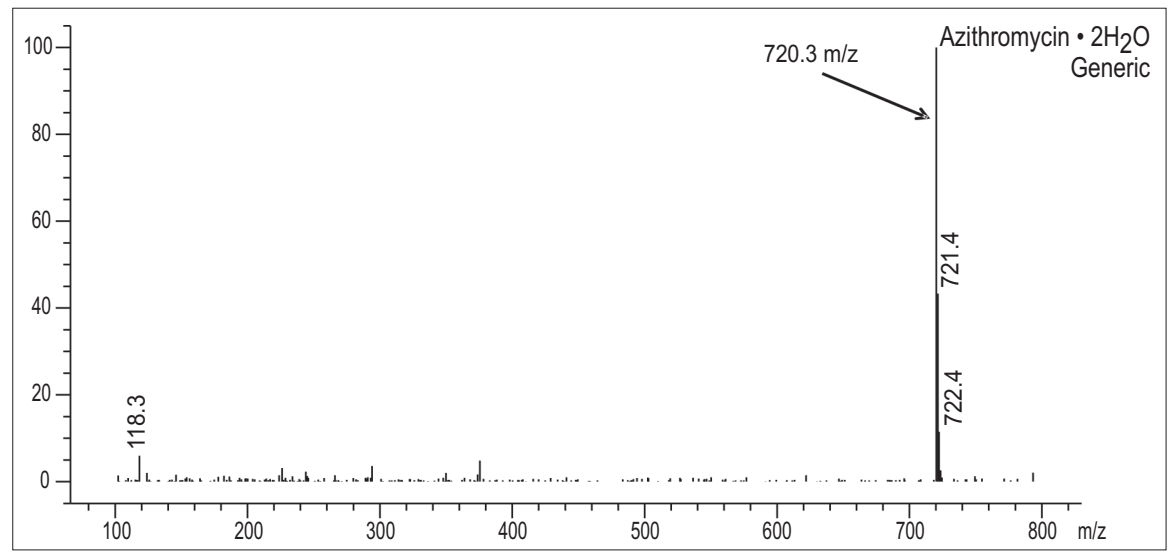


Figure 4. Chemical structure of possible impurities found in the generic formulation of azithromycin dihydrate. (A) 3'-N,N-Di(desmethyl) azithromycin (CAS\#: 612069-27-9, azithromycin EP impurity E), which has molecular weight of $420.9 \mathrm{~g}$ mol-1 and (B) 3'-Des(dimethylamino)-3'-keto azithromycin (CAS\#: 612069-25-7, azithromycin EP impurity N), which has molecular weight of $419.9 \mathrm{~g}$ mol-1.

A

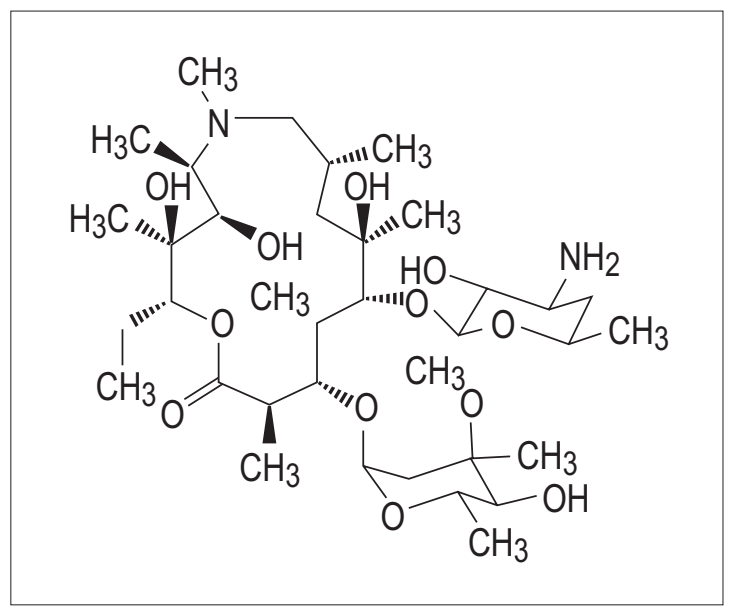

$\mathrm{B}$

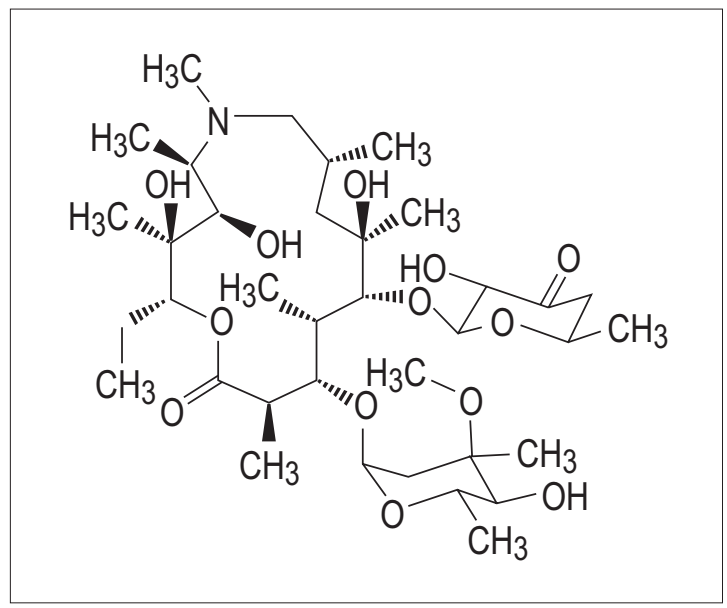

Figure 5. Chromatograms and mass spectrums obtained for (A) standard amoxicillin trihydrate, (B) reference amoxicillin trihydrate and (C) generic amoxicillin trihydrate.

A

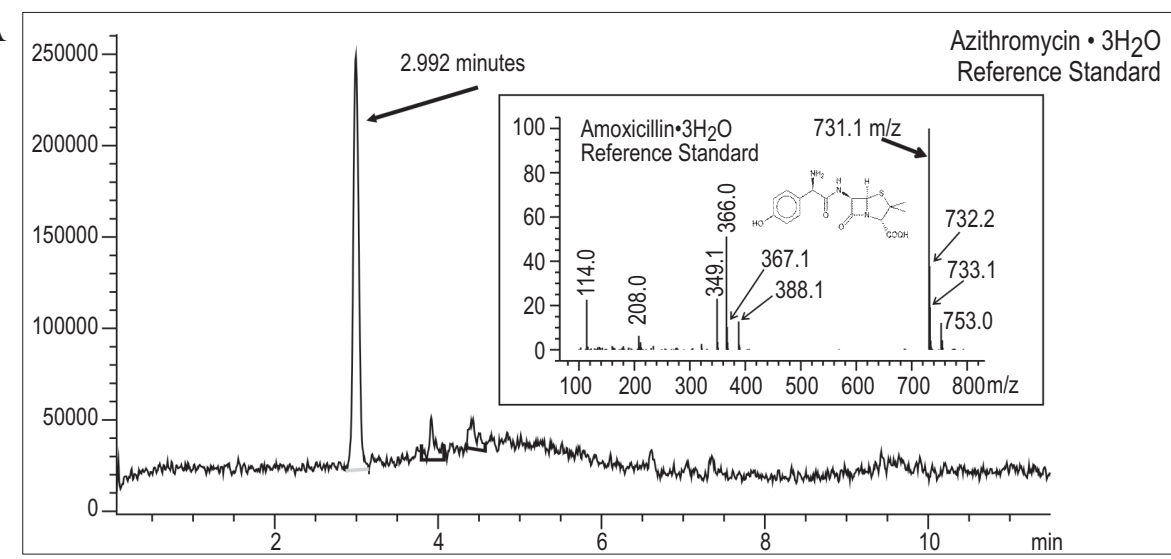

B

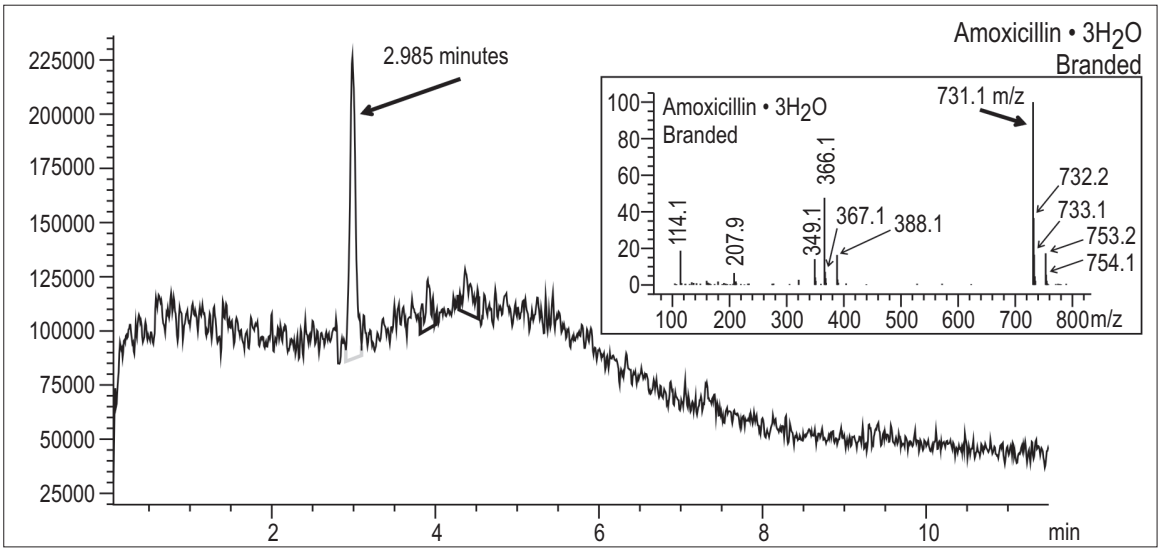




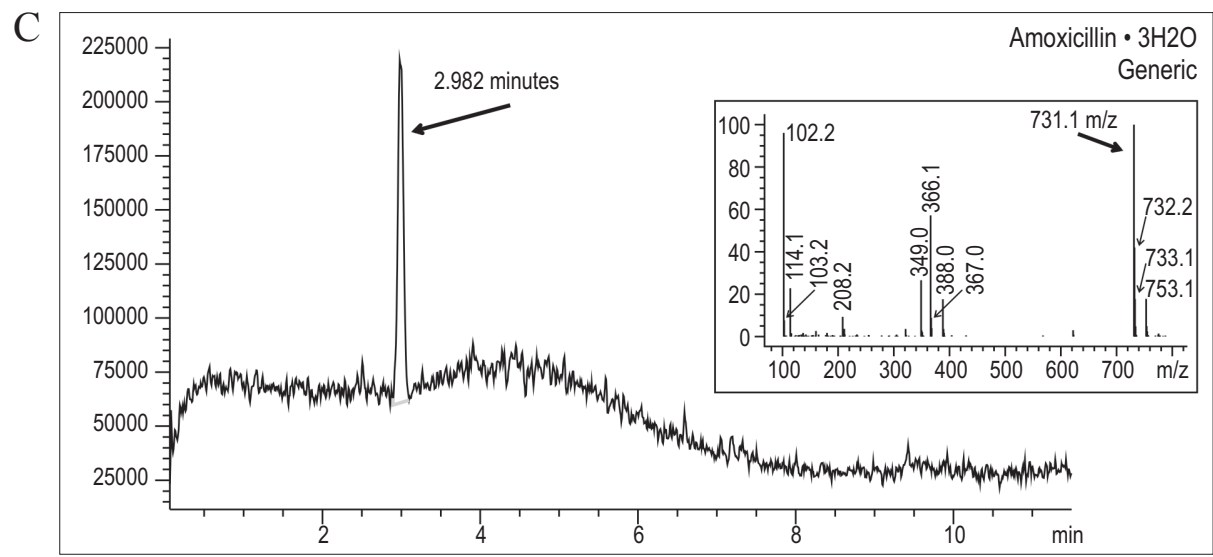

Figure 6 shows the chromatogram (LC-MS) and mass spectra associated with the standard and generic fluconazole.

Figure 6. Chromatogram obtained by LC-MS (SCAN mode) and mass spectra for standard fluconazole (A) and generic fluconazole, which the main peak corresponds to fluconazole (4.840 min) (B).
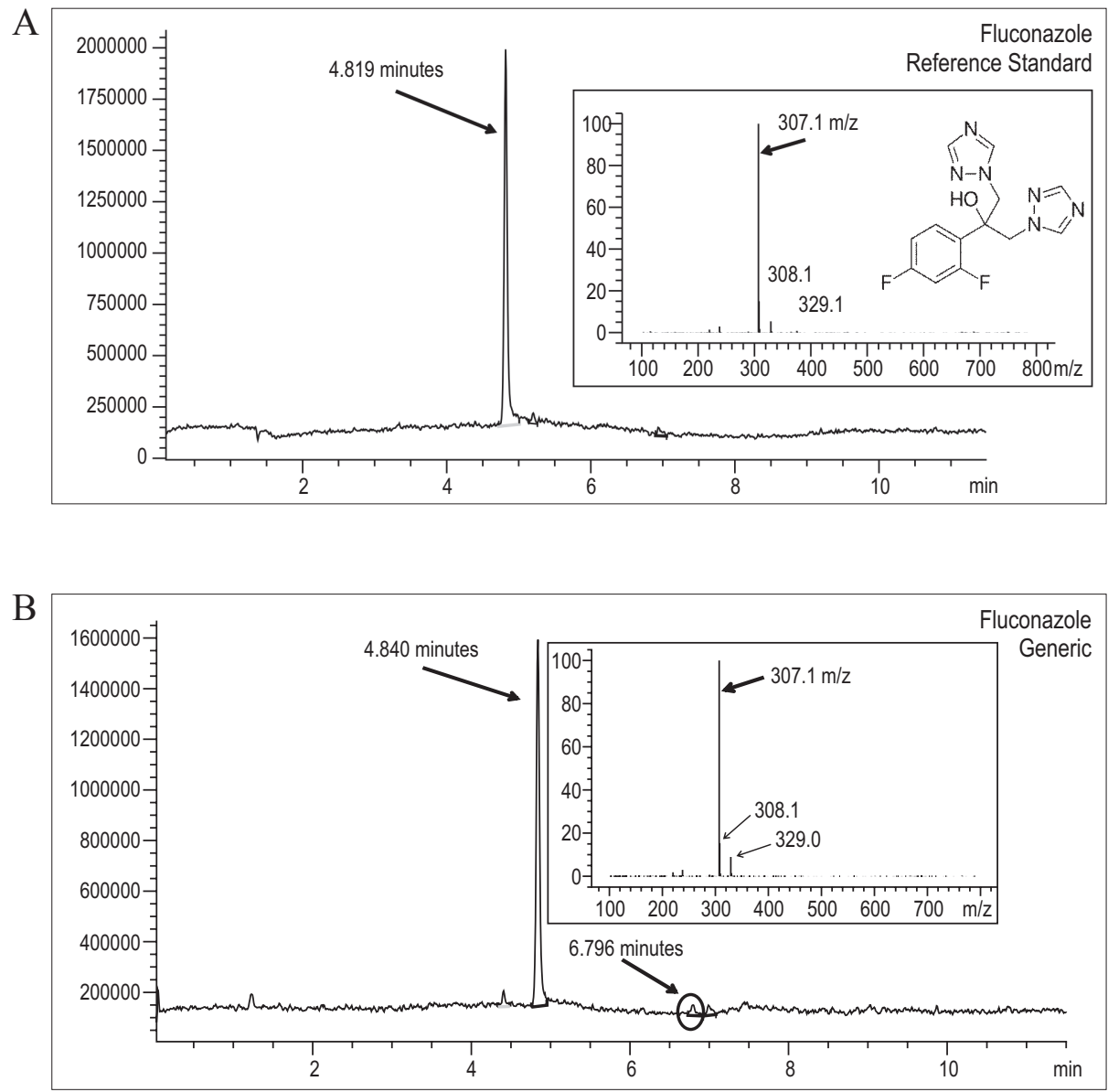
The peak at $4.840 \mathrm{~min}$ corresponds to fluconazole, as evidenced by the characteristic mass-to-charge ratio associated with fluconazole seen in the mass spectrum of this peak (Figure 6), in addition to the comparison with the pure standard of this substance. Additionally, there is a small peak at $6.796 \mathrm{~min}$, which did not have a matching peak in the pure standard. Further analysis of the mass spectrum of this peak (Figure 7) shows a fragment with a molecular weight of $227 \mathrm{~g}$ mol-1. A search of known impurities of fluconazole did not reveal any molecules with the same molecular weight, but it should be noted that this does not mean that any of the known impurities are not present.

Figure 7. Mass spectrum of $6.796 \mathrm{~min}$ peak for generic fluconazole.

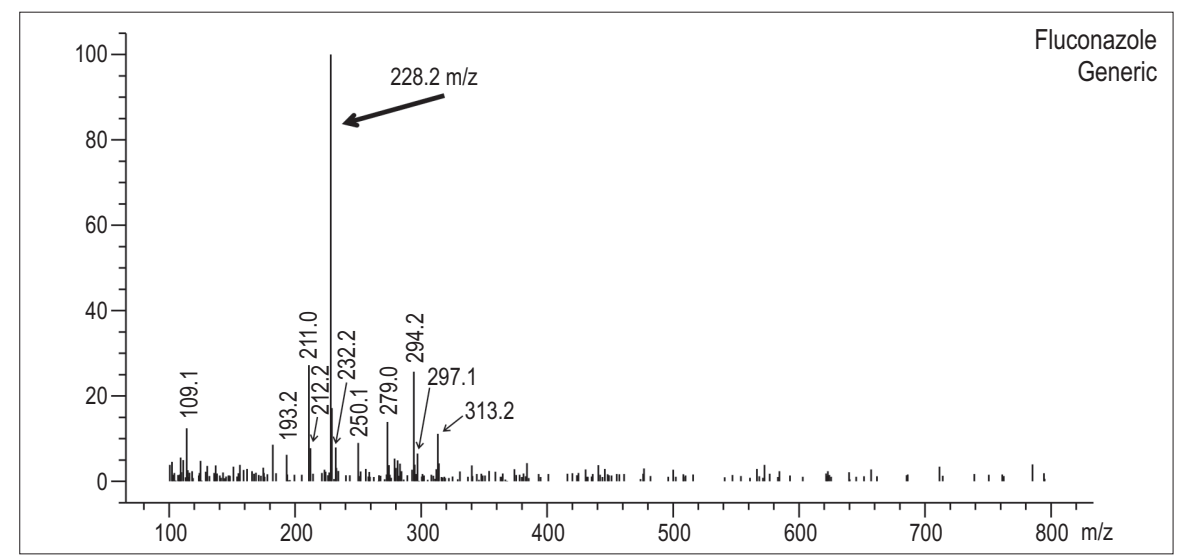

Figure 8 shows the mass spectrum for the pure itraconazole standard, which corresponds to the peak at $8.654 \mathrm{~min}$ from LC-MS chromatogram. The molecular weight of itraconazole is 705.65 $\mathrm{g}$ mol-1. There are also several peaks that differ only by one mass unit: 706.2, 707.2, 708.2, and $710.2 \mathrm{~m} / \mathrm{z}$, which indicate that itraconazole can ionize in several different ways, only differing by the mass of a few hydrogen atoms. It is essential to know when identifying possible impurities - the molecular weight indicated by a mass spectrum is not guaranteed to be the actual molecular weight of that particular chemical entity.

Figure 8. Chromatogram obtained by LC-MS (SCAN mode) and mass spectra for standard itraconazole.

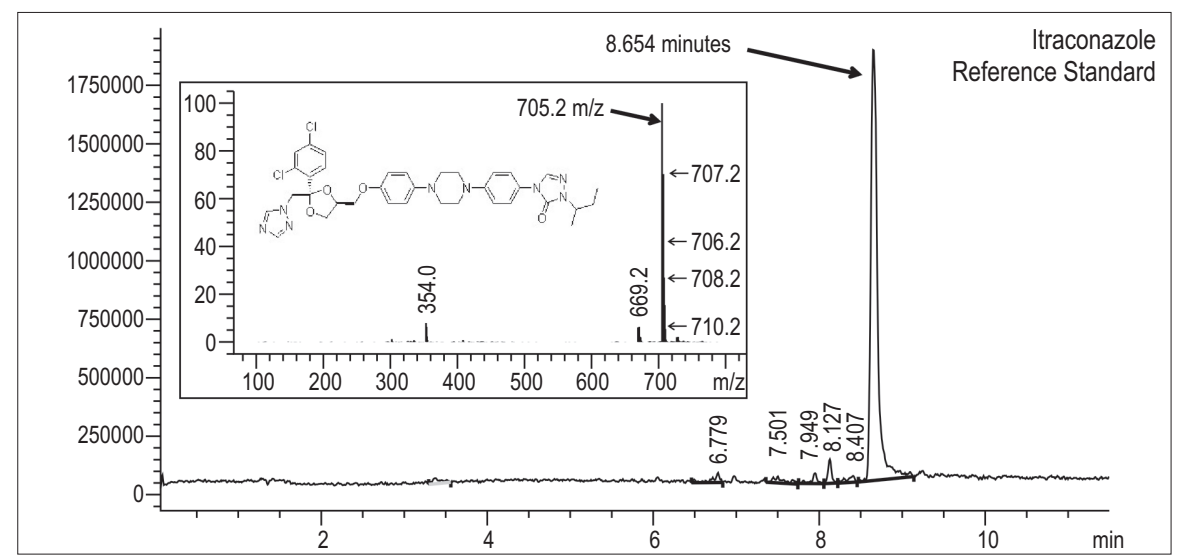


For the generic itraconazole, the peak at 8.663 min corresponds to itraconazole, as evidenced by the characteristic mass-to-charge ratios and pattern associated with itraconazole seen in the mass spectrum of this peak (Figure 9). There are several other small peaks (with retention times shown) that indicate chemical entities that have conjugated moieties. In particular, there is a small peak at $7.853 \mathrm{~min}$ on the LC-
MS scan, which does not have a matching peak in the standard. Analysis of the mass spectrum of this peak (Figure 9C) reveals the presence of a chemical entity with a primary fragment with a mass-to-charge ratio of $408.3 \mathrm{~m} / \mathrm{z}$. As mentioned earlier, it is unclear whether this corresponds to a molecular weight of $407 \mathrm{~g}$ mol-1 or $408 \mathrm{~g}$ mol-1 based on how itraconazole ionizes with ESI.

Figure 9. Chromatogram obtained by LC-MS (SCAN mode) for generic itraconazole (A), Mass spectrum of 8.663 min peak for generic fluconazole (B) and Mass spectrum of 7.853 min peak for generic fluconazole $(\mathrm{C})$.
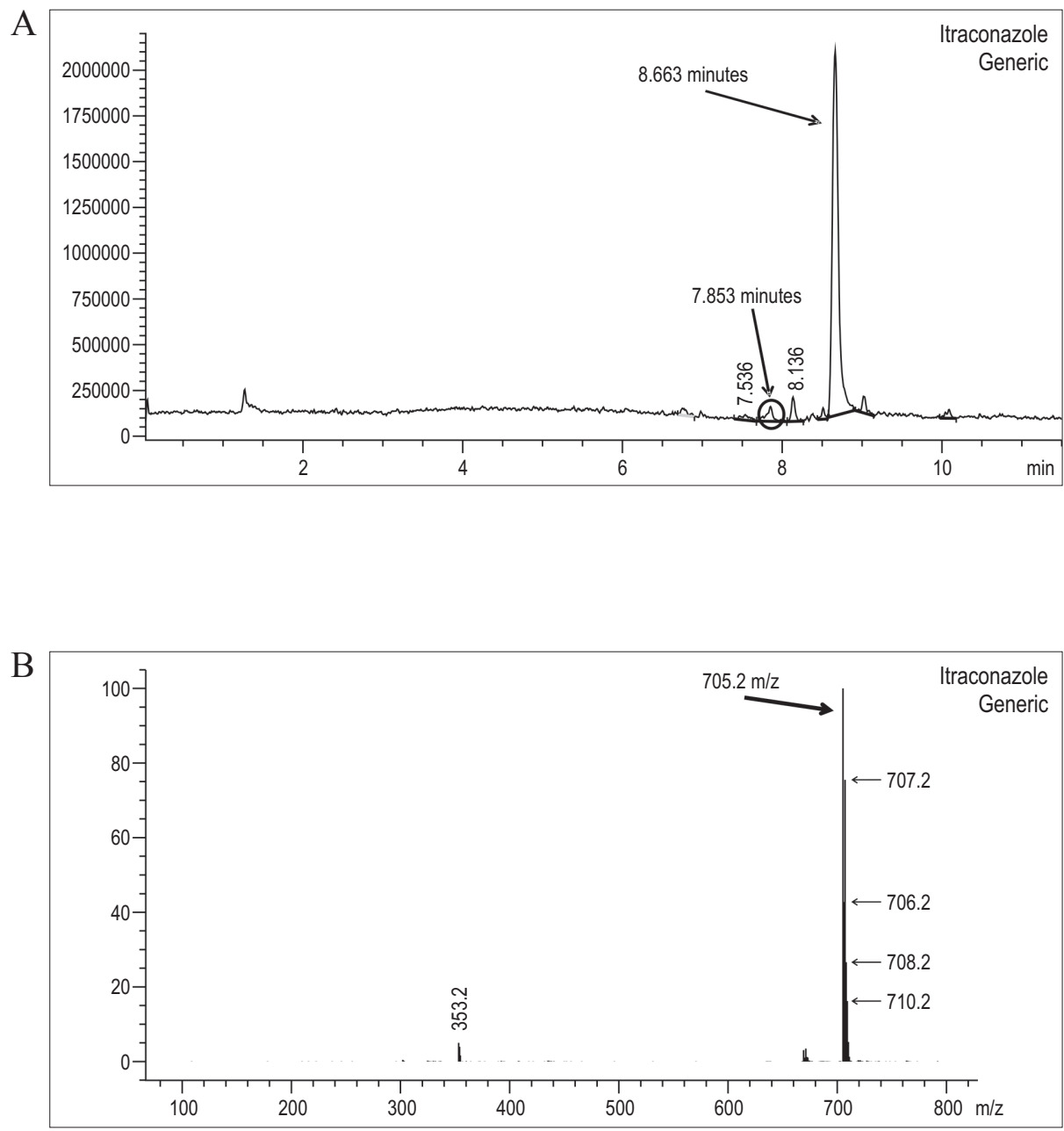


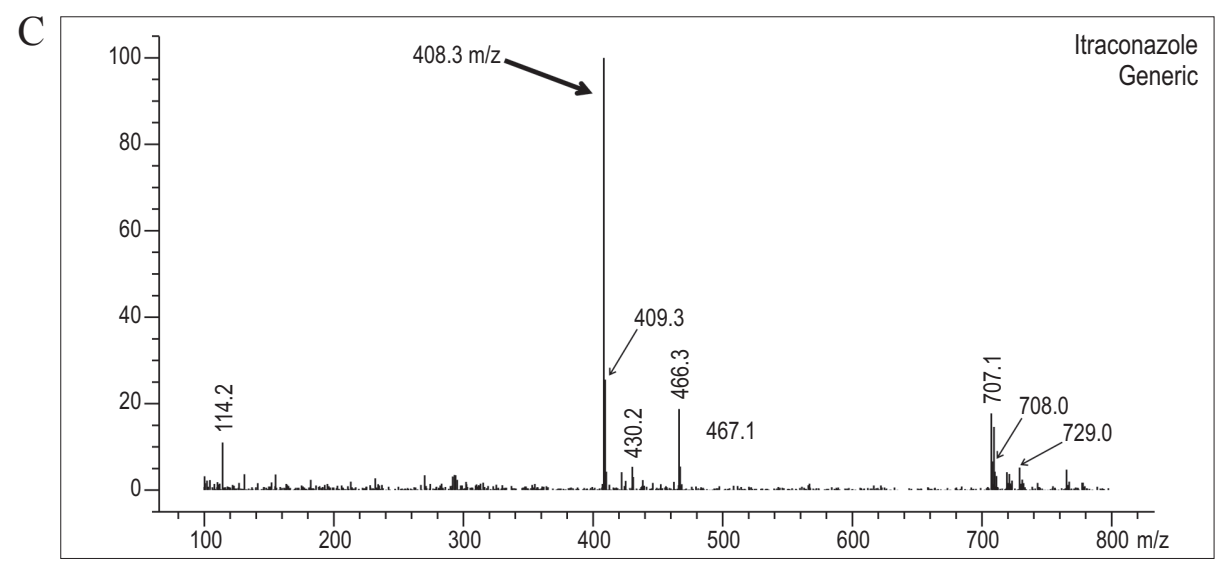

Wharton et al. in 2014 found different molecules with the mentioned molecular weights may be known impurities of itraconazole (21). Two molecules (Figure $10 \mathrm{~A}$ and B) are cistrans isomers: cis-[2-(2,4-Dichlorophenyl)-

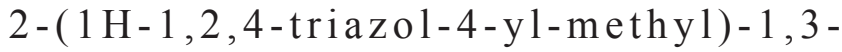
dioxolan-4-yl]methylmethanesulfonate, and trans-[2-(2,4-Dichlorophenyl)-2-(1H-1,2,4triazol-1-yl-methyl)-1,3-dioxolan-4-yl] methylmethanesulfonate, respectively. Both of these molecules have a molecular weight of $408.3 \mathrm{~g}$ mol-1. A third molecule (Figure 10C) is a known impurity according to the European Pharmacopoeia (itraconazole EP impurity A). This molecule is 2- (2-Butyl) -4-\{4-[4-(4-methyloxyphenyl)-piperazin-1-yl]-phenyl $\}-2,4$-dihydro[1,2,4]-triazol-3-one (CAS\#: 252964-68-4) and has a molecular weight of $407.5 \mathrm{~g}$ mol-1.

Figure 10. Structure of (A) cis-[2-(2,4-Dichlorophenyl)-2-(1H-1,2,4-triazol-4-yl-methyl)-1,3-dioxolan4-yl]methylmethanesulfonate (CAS\#: 67914-86-7); (B) trans-[2-(2,4-Dichlorophenyl)-2-(1H-1,2,4triazol-1-yl-methyl)-1,3-dioxolan-4-yl]methyl methanesulfonate (CAS\#: 854372-78-4) and (C) 2-(2Butyl)-4-\{4-[4-(4-methyloxy-phenyl)-piperazin-1-yl]-phenyl\}-2,4-dihydro-[1,2,4]-triazol-3-one(CAS\#: 252964-68-4), known impurities of itraconazole.
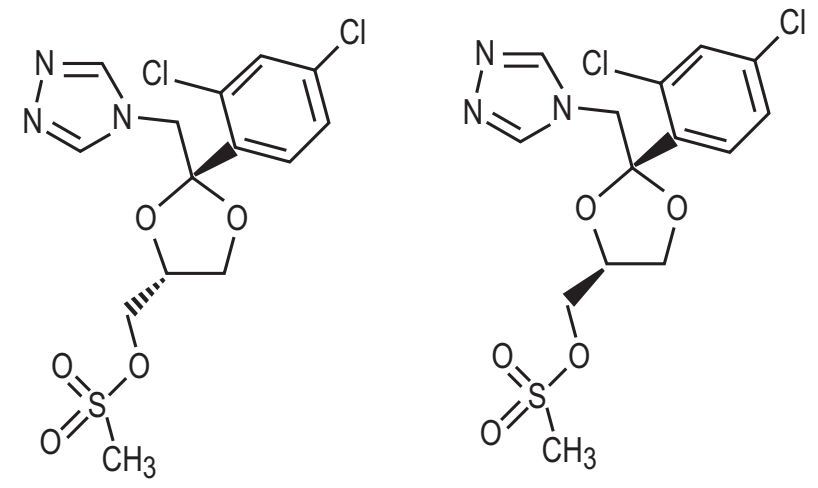<smiles>CCC(C)n1ncn(-c2ccc(N3CCN(c4ccc(OC)cc4)CC3)cc2)c1=O</smiles> 
These data indicate that the generic itraconazole appears to contain an impurity not found in a standard formulation of itraconazole, which and has a prominent mass fragment of $408.3 \mathrm{~m} / \mathrm{z}$.

Given the results discussed above, Table 1 shows a summary of the presence of organic impurities in generic and reference Brazilian medicines, as well as the evaluation of the API content present in each of the generic drugs analyzed.

\section{Conclusion}

We conclude that impurities which can interfere with the safety and efficacy of drugs are not routinely analyzed prior to registration for the treatment of human diseases. It is critical to explore the influence of such generic impurities with respect to their efficacy in addition to a bioequivalence test.

Table 1. Summary of the results of identification of impurities and quantification of the API of generic medicines compared to reference medicines.

\begin{tabular}{|c|c|c|c|c|}
\hline $\begin{array}{l}\text { Therapeutic } \\
\text { Class }\end{array}$ & $\begin{array}{l}\text { Compound } \\
\text { Description }\end{array}$ & $\begin{array}{l}\text { Sample } \\
\text { Impurity* }\end{array}$ & Possible & $\begin{array}{l}\% \text { API vs } \\
\text { Branded* }\end{array}$ \\
\hline \multirow[t]{3}{*}{ Antibiotic } & Amoxicillin trihydrate & Reference & ND & $\mathrm{n} / \mathrm{a}$ \\
\hline & & Generic 1 & ND & 97.7 \\
\hline & Azithromycin dihydrate & Generic 1 & $\begin{array}{l}\text { Azithromycin } \\
\text { EP impurity E, N }\end{array}$ & $\mathrm{n} / \mathrm{a}$ \\
\hline Antifungal & Fluconazole & Generic 1 & $\begin{array}{l}\text { Unknown (mass } \\
\sim 227 \text { g mol-1) }\end{array}$ & $\mathrm{n} / \mathrm{a}$ \\
\hline Itraconazole & Generic 1 & & $\begin{array}{l}\text { cis-trans isomers } \\
\text { of known impurity }\end{array}$ & $\mathrm{n} / \mathrm{a}$ \\
\hline
\end{tabular}

*ND = not detected; $\mathrm{n} / \mathrm{a}=$ not applied.

\section{References}

1. Jain, M., Srivastava, V., Kumar, R., Dangi, V., Hiriyanna S.G., et al. Determination of five potential genotoxic impurities in dalfampridine using liquid chromatography. J Pharmaceut Biomed. 2017;133:27-31.

2. Krakowska, B., Custers, D., Deconinck, E., Daszykowski, M. Chemometrics and the identification of counterfeit medicines-A review. J Pharm Biomed Anal. 2016;127:112-22.

3. Newton, P,N., Green, M.D., Fernandez, F.M. Impact of poor-quality medicines in the 'developing' world. Trends Pharmacol Sci. 2010;31(3):99-101.

4. Fernandez FM, Hostetler D, Powell K, Kaur H, Green MD, Mildenhall DC, et al. Poor quality drugs: grand challenges in high throughput detection, countrywide sampling, and forensics in developing countries. Analyst. 2011;136(15):3073-82.

5. Hollein, L., Kaale, E., Mwalwisi, Y.H., Schulze, M.H., Holzgrabe, U. Routine quality control of medicines in developing countries: Analytical challenges, regulatory infrastructures and the prevalence of counterfeitmedicines in Tanzania. Trac-Trend Anal Chem. 2016;76:60-70.
6. Puig-Junoy, J. Impact of European pharmaceutical price regulation on generic price competition: a review. Pharmacoeconomics. 2010;28(8):649-63.

7. Buckley, G. J., Gostin, L.O. Countering the problem of falsified and substandard drugs. The National Academies Press. 2013:351.

8. Corrao, G., Soranna, D., Arfe, A., Casula, M., Tragni, E., Merlino, L., et al. Are generic and brand-name statins clinically equivalent? Evidence from a real data-base. Eur J Intern Med. 2014;25(8):745-50.

9. Rawlins, M.D. Generic prescribing: unfinished business. The Lancet. 2015;385:219.

10. Deconinck, E., Sacre, P.Y., Courselle, P., De Beer, J.O. Chromatography in the Detection and Characterization of Illegal Pharmaceutical Preparations. J Chromatogr Sci. 2013;51(8):791-806.

11. Erturk S, Aktas ES, Ersoy L, Ficicioglu S. An HPLC method for the determination of atorvastatin and its impurities in bulk drug and tablets. J Pharmaceut Biomed. 2003;33(5):1017-23.

12. Novakova, L., Satinsky, D., Solich, P. HPLC methods for the determination of simvastatin and atorvastatin. TracTrend Anal Chem. 2008;27(4):352-67. 
13. Rodrigues, L.R., de Oliveira, D.N., Ferreira, M.S., Catharino, R.R. In situ assessment of atorvastatin impurity using MALDI mass spectrometry imaging (MALDIMSI). Analytica Chimica Acta. 2014;818:32-8.

14. Taluri, M.V.N.K., Kalyankar, A.R.S. Synchronized separation of atorvastatin — an antihyperlipidemic drug with antihypertensive, antidiabetic, antithrombotic drugs by RP-LC for determination in combined formulations. Journal of Pharmaceutical Analysis. 2012;2(4):285-92.

15. Wang, J., Luzum, J.A., Phelps, M.A., Kitzmiller, J.P. Liquid chromatography-tandem mass spectrometry assay for the simultaneous quantification of simvastatin, lovastatin, atorvastatin, and their major metabolites in human plasma. J Chromatogr B Analyt Technol Biomed Life Sci. 2015;983-984:18-25.

16. Culzoni, M.J., Dwivedi, P., Green, M.D., Newton P.N., Fernandez, F.M. Ambient mass spectrometry technologies for the detection of falsified drugs. Medchemcomm. 2014;5(1):9-19.
17. Katny, M., Frankowski, M. Impurities in Drug Products and Active Pharmaceutical Ingredients. Crit Rev Anal Chem. 2017;47(3):187-93.

18. Dispas A, Desfontaine V, Andri B, Lebrun P, Kotoni D, Clarke A, et al. Quantitative determination of salbutamol sulfate impurities using achiral supercritical fluid chromatography. J Pharmaceut Biomed. 2017;134:170-80.

19. Plumb, R.S., Jones, M.D., Rainville, P., Castro-Perez, J.M. The rapid detection and identification of the impurities of simvastatin using high resolution sub $2 \mathrm{mu}$ m particle LC coupled to hybrid quadrupole time of flight MS operating with alternating high-low collision energy. J Sep Sci. 2007;30(16):2666-75.

20. Chang, Y., Wang, L.X., Li, Y.P., Hu, C.Q.Factors Influencing the HPLC Determination for Related Substances of Azithromycin. J Chromatogr Sci. 2016;54(2):187-94.

21. Wharton, M., Geary, M., Sweetman, P., Curtin, L., O'Connor, N. Rapid liquid chromatographic determination of itraconazole and its production impurities. J Chromatogr Sci. 2014;52(3):187-94. 


\title{
Lethal Ovitrap CIMATEC: A New Trap for Arbovirus Transmitting Mosquitoes
}

\author{
Eduardo Oyama*; Daniel Mota \\ Health Institute of Technology - SENAI-CIMATEC; Salvador, BA, Brazil
}

\begin{abstract}
A lot of countries have difficulty in combating Ae. aegypti, due to the high adaptability of this mosquito to the urban area. The National Program for Dengue Control (PNCD) is responsible for allocating the most activities to combat Ae. aegypti in districts of Brazil (basic sanitation, education, chemical control). Despite the technological advances in the $21^{\text {th }}$ century, there was little social commitment with the conception of a formal device in the fight against $\mathrm{Ae}$. aegypti. Senai-Cimatec developed a trap (Lethal Ovitrap Cimatec ${ }^{\mathrm{TM}}$ ) based on new technologies to control Aedes aegypti. So, the aim of this study was to compare the traditional traps on the market with the LOC ${ }^{\mathrm{TM}}$ trap, created by Cimatec. We performed two experiments to evaluate the performance of the traps against the mosquitoes. The tests occurred in a monitored and closed environment at the Central Laboratory of Bahia (Entomology Laboratory) (LACEN/BA). The larvae, water, and substrate for the experiment in the three containers had the same origin; three cages were kept in the entomology sector with the same conditions of temperature and humidity. The results showed that LOC $^{\mathrm{TM}}$ has several advantages when compared to the traditional traps, such as: capacity to eliminate the immature forms of the vector in a few hours; entrapment and extermination of larvae and/or adults forms by asphyxiation; high lethality for mosquitoes and ability to reduce the Aedes population in an area by removing from the environment future generations of mosquitoes; installation; it is attractive to mosquitoes; no needs of weekly monitoring; no power consumption; simple manipulation and low-cost; water as a protection factor and not as a risk factor; it does not use insecticide or any toxic agent harmful to human health. So, the use of $\mathrm{LOC}^{\mathrm{TM}}$ has advantages over traditional traps, directing the biotechnology market to new solutions with low-cost, easy to handle and non-toxic to man and the environment in the fight agains Ae. aegypti.
\end{abstract}

Keywords: Traditional Ovitrap. LOC ${ }^{\mathrm{TM}}$. Arboviruses. Ae. aegypti.

The impacts of the current epidemiological scenario of arboviruses in Brazil, characterized by Dengue, the dissemination of ZIKV and CHIKV virus, and the re-emergence of FMV in the ExtraAmazon region were enough to establish a public health emergency by the Ministry of Health and the World Health Organization [1].

Brazil recorded 113,381 suspected cases of Dengue Fever, 43,010 of Chikungunya, 7,911 of ZIKV Fever and 3,140 cases of Yellow Fever according to the Ministry of Health (2017) [2]. In that period, 17 deaths from Dengue, 9 deaths from CHIKV, and 240 deaths from Yellow Wild Fever were confirmed.

Received on 17 February 2019; revised 23 February 2019. Address for correspondence: Dr. Eduardo Oyama. Avenida Orlando Gomes, N. 1845, Piatã. Zip Code: 41650-010. Salvador, Bahia, Brazil. Phone: (+55 71) 3879-5501.E-mail: eduoyama@gmail.com.

J Bioeng. Biotech. Appl. Health 2019;2(2):47-53.

(C) 2019 by SENAI CIMATEC. All rights reserved.
The entomological situation reveals that $A e$. aegypti is found dispersed in most Brazilian cities [3]. The Ministry of Health has tried to implement control actions for this vector; however, the results have not been satisfactory, since infestation by remains high [4]. Only four Brazilian states (Acre, Amapá, Piauí and Sergipe) have not yet registered the presence of Ae. Albopictus [5]. However, most Brazilian states have sufficient Ae. aegypti to initiate and maintain the transmission of DENV and other arboviruses.

A lot of countries have difficulty in combating Ae. aegypti, due to the high adaptability of this mosquito to the urban area [6]. In the last two decades, the intensification of the vector combat has been carried out mainly through chemical control, which has led to a resistance of Ae. aegypti to many groups of insecticides [7]. Therefore, additional effort from the health sector is required, with an estimated cost of $\mathrm{R} \$ 1$ million per day [8]. 
The National Program for Dengue Control (PNCD) is responsible for allocating the most activities to combat Ae. aegypti in the districts of Brazil, such as investment in basic sanitation and education [3], chemical control, and other essential performances [6].

The areas of water accumulation (focal treatment) applied chemical control with larvicidal action. The control of adult insects uses two chemical control modalities: the spraying of insecticides with residual effect in the walls of breeding places, which are susceptible to the proliferation of immature forms (larvae and pupae), denominated perifocal treatment; and the spatial treatment of insecticide by ultralow volume (UVB), indicated for outbreak and epidemic situations [1].

New strategies to combat vectors have been adopted to reduce the population of mosquitoes to minimize the impact of chemical larvicides on human health and in the environment, such as biological control based on the use of natural enemies or biological toxins. Different groups of organisms (bacteria, protozoa, fungi, and viruses) with potential use against Ae. aegypti have been evaluated. Among them, Bacillus thuringiens isisraelensis (B.t.i) and Bacillus sphaericus (B.s.) have been used to control mosquitoes. B.t.i has been used in the control of Ae. aegypti because it is effortless to prepare the formulation and because of the properties that allow its growth on a wide variety of substrates [10].

Environmental management should be considered an equally relevant strategy for mosquitos' controls. Among the ecological management actions, there are the elimination and removal of breeding sites in the home environment, the storage, collection and final disposal of solid waste, control of the border vegetation of the breeding sites, drainage and earth moving services, as well as investment in the primary sanitation system, and the participation and education of the community [11].

More recently, full integration of control alternatives has been devised, combining physical and biological management control: the use of specific adulticides and the application of alternative (natural) larvicides with low impact on human health and in the environment. However, this kind of strategies cannot be dissociated from education of the community to achieve success in combating vector insects [12].

Despite the technological advances in the $21^{\text {th }}$ century, with the use of new machines, materials, and production processes, there was little social commitment with the conception of a formal device in the fight against Ae. aegypti. Little effort was made to create tools, such as traditional traps, to combat the mosquitoes.

Senai-Cimatec developed a trap (Lethal Ovitrap Cimatec $^{\mathrm{TM}}$ ) based on new technologies to control Aedes aegypti.

The aim of this study was to compare the traditional traps on the market with the $\mathrm{LOC}^{\mathrm{TM}}$ trap, created by Cimatec, for the ability to visualize the presence of the eggs and eliminate larval forms of Ae. aegypti.

\section{Traditional Traps}

The traditional oviposition trap consists of a black-plastic container with a large hole (Figure 1). The volume capacity is $300 \mathrm{~mL}$, but only 200 $\mathrm{mL}$ of water is added, equivalent to the size of the LOC $^{\mathrm{TM}}$ trap. The Eucatex palette $-6.0 \mathrm{~cm}$ by $2.5 \mathrm{~cm}$ plywood - is placed inside the trap, similar to that used in $\mathrm{LOC}^{\mathrm{TM}}$.

\section{Lethal Ovitrap Cimatec $^{\mathrm{TM}}\left(\right.$ LOC $\left.^{\mathrm{TM}}\right)$}

The LOC $^{\mathrm{TM}}$ trap is made up of a transparent cylindrical plastic container, containing two pieces: a cap with a recess and a funnel in the center. The cover has three openings, through which the female mosquitoes enter to perform oviposition. Besides being the access door to the vector, the cover protects the trap from objects or other materials that may fall in it and clog it. The funnel is tilted, and the outer wall is roughened to increase egg adhesion because Aedes aegypti 
Figure 1. Traditional Ovitrap.

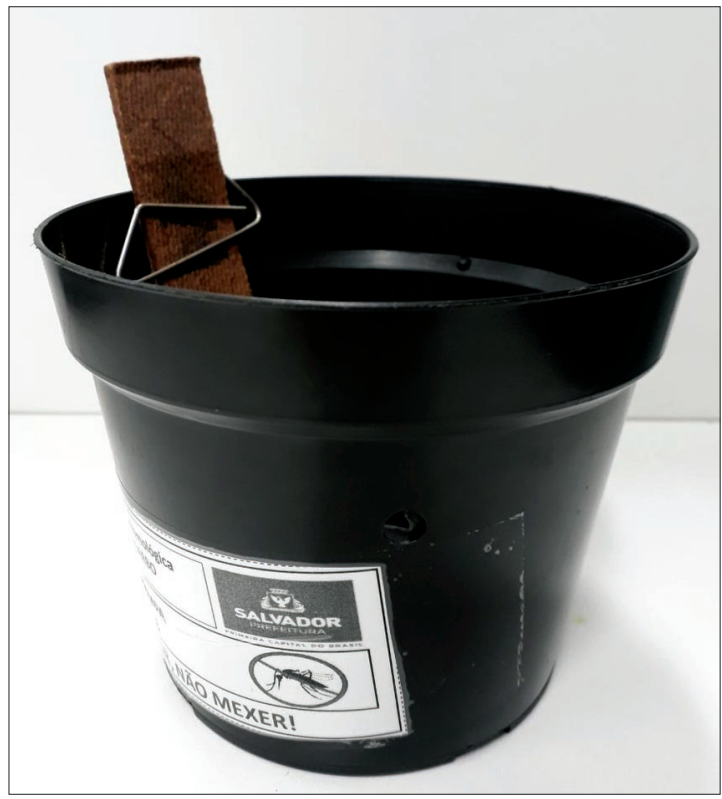

females prefer to lay eggs on rough walls (Figure 2).

The $\mathrm{LOC}^{\mathrm{TM}}$ does not have sensors, light, nor a mechanical barrier nor a physical barrier. There is no card with glue, insecticide, nor a fan and attractive chemicals. It is a simple trap, easy to handle, low-cost and uses no energy in its operation.

The trap is excellent, with a quality certification guaranteed by the responsible institutions, which ensure its long-term durability in combating vectors.

\section{$\underline{\mathrm{LOC}^{\mathrm{TM}}} \stackrel{\text { Operation }}{\mathrm{T}}$}

The Ae. aegypti female deposits the eggs on the wall of the funnel. In contact with the water, the eggs will hatch, and the larvae will emerge. The newborn mosquito larvae descend to the bottom of the container, looking for food passing through the rod. However, the larvae need to return to the surface to breathe, but they cannot reach the top of the rod, which has a $45^{\circ}$ degree inclination and is usually submerged, and get trapped and die by asphyxiation.

When the level of the container is not full, the larvae tend to survive to adult form, but the mosquitoes also cannot get out because they even
Figure 2. LOC trap.

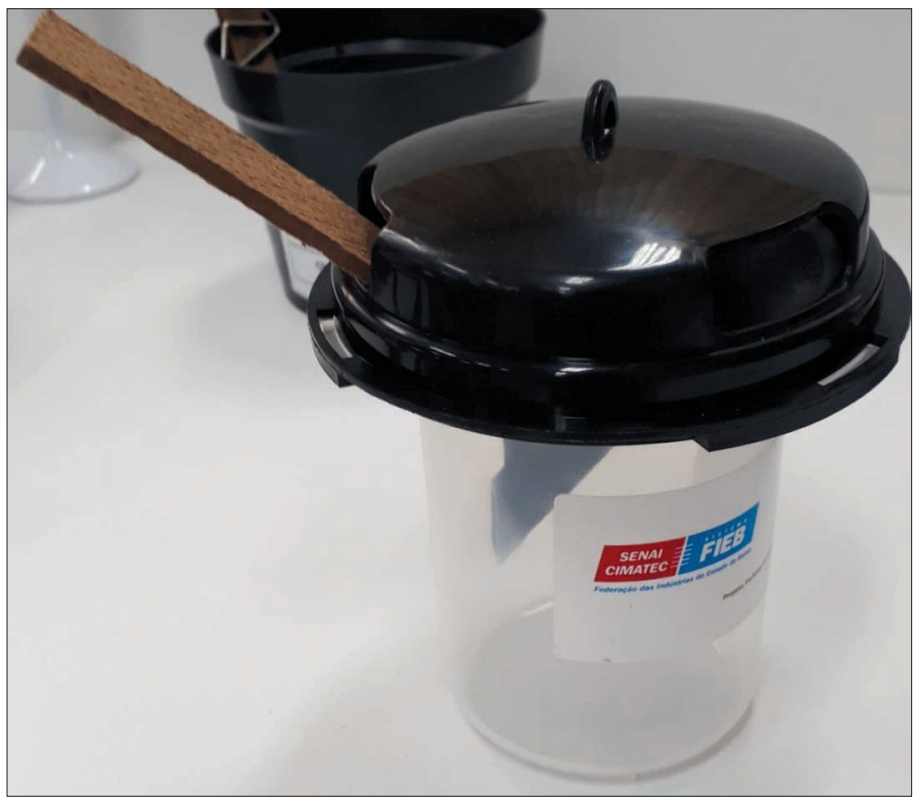

cannot reach the top of the rod, and die inside the container. The cover must be unscrewed to release the water with the dead larvae or insects to remove the dead larvae or adults.

$\mathrm{LOC}^{\mathrm{TM}}$ uses the color black and the presence of water to attract the Culicidae. The females of the Ae. aegypti are invited to the trap and lay the eggs in the funnel. The rounded form and the dark color are considered visual stimuli since they simulate a quiet place to rest for the adult mosquitoes to lay their eggs.

In this trap, any egg that hatches is unable to release the adult mosquito into the external environment due to its internal design. Thus, this trap can reduce the population of Ae. aegypti in urban areas by collecting eggs, trapping larvae and pupae, hampering the emergence of adult mosquitoes.

\section{Installation of $\mathrm{LOC}^{\mathrm{TM}}$}

The trap must be installed at ground level or the height of 1.20 to $1.50 \mathrm{~cm}$ from the floor and can be hung by the handle or under a flat surface, with natural water. The trap should be placed preferably indoors or in the perimeter, in shaded places, protected from direct rain, and with little movement of people or animals. 
$\mathrm{LOC}^{\mathrm{TM}}$ requires that the owner maintain the trap full of water. If the trap is full, it will kill the larvae within a few hours later. On the other hand, if it is partially complete, the larvae will survive, but the adults will die from drowning after exhaustion.

\section{The Experiments}

We performed two experiments to evaluate the performance of the traps against the mosquitoes. The tests occurred in a monitored and closed environment at the Central Laboratory of Bahia (Entomology Laboratory) (LACEN/BA). The larvae, water, and substrate for the experiment in the three containers had the same origin; keeping three cages in the entomology sector with the same conditions of temperature and humidity.

We collected a total of 90 larvae of Culicidae from a single artificial local at LACEN/BA. These larvae were introduced into three (03) traps in separate cages:

Trap 1: Black Hole Trap was filled with water, i.e., no oxygen was available inside for larval breathing. Thirty larvae at different stages $\left(2^{\text {nd }}, 3^{\text {rd }}\right.$, and $4^{\text {th }}$ stages) were introduced. It was observed that the larvae descended immediately through the funnel to the bottom of the container. The trap was placed inside cage 1 to ensure the containment of future adults in case of larvae survival. Larval return to the surface by the funnel was not observed.

Trap 2: Black Hole trap was partially filled with water. Thirty larvae at different stages $\left(2^{\text {nd }}, 3^{\text {rd }}\right.$, and $4^{\text {th }}$ stages) were introduced. The larvae were introduced into the funnel with the help of a pipette, where it was observed that they immediately entered the container. The trap was put into cage 2. The return of the larvae to the surface via the funnel was also not observed.

Trap 3: An open cylindrical pot was partially filled with water, without a funnel. Thirty larvae in $2^{\text {nd }}$, $3^{\text {rd }}$, and $4^{\text {th }}$ stages were introduced. The container was put into cage 3 .
Three cages were used in the laboratory environment. Ten females and two males of $A e$. aegypti were put into each cage. The females were inserted engorged on the exposure date $(01 / 07 / 2016)$. Two oviposition traps were placed within each cage: the traditional ovitrap and the $\mathrm{LOC}^{\mathrm{TM}}$ trap. In both traps, a Eucatex palette was inserted.

Reading for the presence and number of eggs in the palette was performed daily from 07/04 to $07 / 08$ (five days) for one week from the start date of the experiment $(01 / 07 / 2016)$. The time recommended to monitoring the ovitraps in the field. A magnifying glass counted the eggs of the mosquitoes.

In cage one (1), the $\mathrm{LOC}^{\mathrm{TM}}$ had more eggs (48 eggs) in the palette than the traditional ovitrap palette (45 eggs) (Table 1). In cage two (2), the traditional ovitrap had more eggs (122) than the LOC $^{\mathrm{TM}}$ trap (57 eggs) (Table 2). In cage three (3), the LOC ${ }^{\mathrm{TM}}$ trap had more eggs in the palette (147) than the traditional lovitrap (25 eggs) (Table 3 ). In terms of the total number of eggs collected, the LOC $^{\mathrm{TM}}$ trap had more eggs (252) compared to the traditional trap (192) (Table 4).

Water was added to the traps to the limit of the container on the last day of reading $(07 / 08 / 16)$ for the presence and quantification of eggs $(07 / 08)$ to cause the contact of the water with the eggs in the palettes to hatch and release the larvae.

Larvae counting began on 07/04/16. In the three cages of the experiment it was observed that the $\mathrm{LOC}^{\mathrm{TM}}$ trap did not present any live $A e$. aegypti larvae: we counted twenty-two dead $A e$. aegypti larvae in cage 1; fifteen dead Ae. aegypti in $1^{\text {st }}$ stage larvae in cage 2; and fifty-two dead $A e$. aegypti in $1^{\text {st }}$ stage larvae in cage 3 (Table 5).

Cage three (3) presented adult forms of Culicidae, no winged forms of the vector were observed in cages 1 and 2. No Culicidae survived in any of the three cages, indicating that the $\mathrm{LOC}^{\mathrm{TM}}$ worked both full and partially filled with water.

This experiment was repeated in the laboratory to confirm results and then applied in the field, to validate the project and establish final adjustments, completing the design stage. 
Table 1. Number of Aedes aegypti eggs by traps in cage 1 (traditional ovitrap x LOC ${ }^{\mathbf{T M}}$ ).

\begin{tabular}{ccc}
\hline Read Date (Eggs) & Traditional Ovitrap & LOC $^{\mathbf{T M}}$ \\
\hline $07 / 04 / 16$ & 0 & 0 \\
$07 / 05 / 16$ & 0 & 0 \\
$07 / 06 / 16$ & 19 & 16 \\
$07 / 07 / 16$ & 0 & 0 \\
$07 / 08 / 16$ & 26 & 32 \\
\hline Total & $\mathbf{4 5}$ & $\mathbf{4 8}$ \\
\hline
\end{tabular}

Table 2. Number of Aedes aegypti eggs by traps in cage 2 (traditional ovitrap x LOC ${ }^{\mathbf{T M}}$ ).

\begin{tabular}{ccc}
\hline Read Date (Eggs) & Traditional Ovitrap & LOC $^{\text {TM }}$ \\
\hline $07 / 04 / 16$ & 0 & 0 \\
$07 / 05 / 16$ & 0 & 0 \\
$07 / 06 / 16$ & 17 & 15 \\
$07 / 07 / 16$ & 0 & 0 \\
$07 / 08 / 16$ & 105 & 42 \\
\hline Total & $\mathbf{1 2 2}$ & $\mathbf{5 7}$ \\
\hline
\end{tabular}

Table 3. Number of Aedes aegypti eggs by traps in cage 3 (traditional ovitrampa x LOC ${ }^{\text {TM}}$ ).

\begin{tabular}{ccc}
\hline Read Date (Eggs) & Traditional Ovitrap & LOC $^{\text {TM }}$ \\
\hline $07 / 04 / 16$ & 0 & 0 \\
$07 / 05 / 16$ & 25 & 147 \\
$07 / 06 / 16$ & 0 & 0 \\
$07 / 07 / 16$ & 0 & 0 \\
$07 / 08 / 16$ & 0 & 0 \\
\hline Total & $\mathbf{2 5}$ & $\mathbf{1 4 7}$ \\
\hline
\end{tabular}

Table 4. Total of Aedes aegypti eggs by traps (traditional ovitap x LOC ${ }^{\text {TM }}$

\begin{tabular}{ccc}
\hline Cages & Traditional Ovitrap & LOC $^{\text {TM }}$ \\
\hline 1 & 45 & 48 \\
2 & 122 & 57 \\
3 & 25 & 147 \\
\hline Total & $\mathbf{1 9 2}$ & $\mathbf{2 5 2}$ \\
\hline
\end{tabular}

Table 5. Total of Aedes aegypti larvae in LOC ${ }^{\text {TM }}$ traps.

\begin{tabular}{ccc}
\hline Cages & \multicolumn{2}{c}{ LOC $^{\text {TM }}$} \\
\cline { 2 - 3 } & Live larvae & Dead larvae \\
\hline 1 & 0 & 22 \\
2 & 0 & 15 \\
3 & 0 & 52 \\
\hline Total & $\mathbf{0}$ & $\mathbf{8 9}$ \\
\hline
\end{tabular}




\section{Comparison Between $\mathrm{LOC}^{\mathrm{TM}}$ and Traditional Ovitraps}

The $\mathrm{LOC}^{\mathrm{TM}}$ project was carried out in stages dependent on each other, involving literature review, laboratory and field tests, to consolidate a marketable, efficient and compatible product for the needs of the community in the combat of $A e$. aegypti.

The initial phase of the design process included the definition of the problem, a result of the consumer's need. This stage is crucial and decisive for the development of the method. It addressed a current issue in daily life, the incidence of dengue, which persists despite government efforts and campaigns. First of all, a trap to capture dengue vectors was chosen to be redesigned.

The second phase consisted of the analysis of traps existing in the market, i.e., the collection of data on already existing products. The study of all the data collected on commercial traps provided suggestions of what should not be done and what needed to be improved.

Formal studies helped identify alternatives to solve the problem in the phase of alternative models and sketches. Thus, the pre-selected options were analyzed to establish the best set of improvements for the final prototype. We did a study of economic feasibility and sale price after selecting the best alternative that fully met consumer needs and project specifications, and in parallel, the drawings for the construction of the prototype.

In the fight against Ae. aegypti and Aedes albopictus, no trap is recommended by the National Program for Dengue Control. There is also no commercially available trap sufficiently capable of decreasing the vector population and thus reducing dengue transmission. The trap created by our group from Cimatec (Lethal Ovitramp Cimatec $^{\mathrm{TM}}$ ) is better than traditional traps on the market.

The $\mathrm{LOC}^{\mathrm{TM}}$ is a trap that can also be used in monitoring and early detection of Dengue and Yellow Fever vectors, such as larval traps (larvae trap) and ovitraps (egg traps). LOC $^{\mathrm{TM}}$ is a lethal trap with a function to reduce the Aedes population in the environment and future generations of mosquitoes.

If compared to the traditional ovitrap, as our study showed, it contains functional and aesthetic improvements. One of the main differentials of this trap is the angle in the nozzle of the funnel, which is the main item responsible for the dispensing with the sieve. As a result, the constant handling of the trap is not required, reducing the risk of mishandling and malfunctioning.

Existing traps in the market were essential in aiding the design of $\mathrm{LOC}^{\mathrm{TM}}$. For example, we mention the funnel, which is located above the trap in the $\mathrm{LOC}^{\mathrm{TM}}$, so the volume of water in the trap causes the death of the captured larvae in only a few hours. $\mathrm{LOC}^{\mathrm{TM}}$ can, therefore, reduce Aedes vectors, which can have a huge impact on public health.

$\mathrm{LOC}^{\mathrm{TM}}$ has several advantages when compared to the traditional traps, such as: capacity to eliminate the immature forms of the vector in a few hours; entrapment and extermination of larvae and/or adults forms by asphyxiation; high lethality for mosquitoes and ability to reduce the Aedes population in an area by removing from the environment future generations of mosquitoes; installation, since it can be installed in different contexts and at different heights; it is attractive to mosquitoes - dark color of cover and funnel, and presence of water; no needs to be monitored weekly; no power consumption; simple manipulation and low-cost; water as a protection factor and not as a risk factor; it does not use insecticide or any toxic agent harmful to human health.

So, the use of $\mathrm{LOC}^{\mathrm{TM}}$ has advantages over traditional traps, directing the biotechnology market to new solutions with low-cost, easy to handle and non-toxic to man and the environment in the fight agains Ae. aegypti.

\section{References}

1. Donalisio, M.R., Freitas, A.R., Von Zuben A.P.B. Arboviroses emergentes no Brasil: desafios para a clínica e implicações para a saúde pública. RevSaude Publica. 2017; 51: 30 . 
2. Ministério da Saúde (BR). Boletim Epidemiológico Secretaria de Vigilância em Saúde. Monitoramento dos casos de dengue, febre de chikungunya e febre pelo vírus Zika até a Semana Epidemiológica 15, Volume $48 \mathrm{n}^{\circ} 14$, Brasília: Ministério da Saúde; 2017.

3. Brasil. Ministério da Saúde. Relatório sobre a Dengue. Brasília, 2010.

4. Brasil. Ministério da Saúde. Fundação Nacional de Saúde.Programa Nacional de Controle da Dengue (PNCD). 2a ed. Brasília, 2002, 32p.

5. Aguiar, D.B. et al. Primeiro registro de Aedes albopictus (Diptera: Culicidae) em Roraima, Brasil. Acta Amazônica 2008;38(2):357-60.

6. Teixeira, M.G., etal. Sentinel areas: Public Health surveillance strategy. Cadernos de Saúde Pública 2002;18(5): 1189-95.

7. Brogdon, W.G., McAllister, M. Insecticide resistance and vector control. Emerging Infectious Disease 1998;4:605-13.
8. Brasil. Ministério da Saúde. Fundação Nacional de Saúde. Programa Nacional de Controle da Dengue (PNCD). $2^{\mathrm{a}}$ ed. Brasília: Fundação Nacional de Saúde, 2005.

9. Ministério da Saúde. Secretaria de Vigilância em Saúde. Dengue no Brasil. Informe Epidemiológico, Brasília, novembro de 2009, 10p.

10. Gubler, D.J. Epidemic Dengue/Dengue hemorrhagic fever as a public health, social and economic problem in the $21 \mathrm{st}$ century. Trends Microbiol. 2002;10:100-3.

11. Andrade, C.S.F., Brassolatti R.C., Santos, L.U. Educação para o manejo integrado dos vetores da dengue. Manual UNICAMP. Campinas, 36pp.1998.

12. Axtell, R.C. Principles of integrated pest management (IPM) in relation to mosquito control. Mosquito News 1979;39(4): 709-18. 


\title{
Identification of Sex Using Linear Skull Measures: The Importance of Imaging in Biotechnology
}

\begin{abstract}
Alile Carmo ${ }^{1 *}$; Ana Carolina Mariz² Leandro Santos $^{3}$; Marianna Torres ${ }^{4}$; Raí Santos ${ }^{5}$; Roberto Monteiro ${ }^{6}$ ${ }^{1}$ University Center CIMATEC, Department of Computational Modeling and Industrial Technology; ${ }^{2}$ Ana Carolina Ramos Mariz, Federal University of Bahia, Institute of Health, Dentistry Department, ${ }^{3}$ Leandro Brito Santos, State University of Bahia; ${ }^{4}$ Marianna Torres, Federal University of Bahia, Institute of Health, Dentistry Department; ${ }^{5}$ Rai Faustino Miranda Santos, University Center CIMATEC, Department of Computational Modeling and Industrial Technology; ${ }^{6}$ Roberto Luiz Souza Monteiro, University Center CIMATEC, Department of Computational Modeling and Industrial Technology; Salvador, Bahia, Brazil
\end{abstract}

There are several methods used in the identification process of human remains. The most of them are based on comparing of antemortem and postmortem data available. Although the technique of fingerprinting is considered more accurate in many cases, it cannot be used when the bodies are mutilated, decomposed, burned, or fragmented. This article aims to compare the metric values obtained by Galvão (1994) and Saliba (2001) to differentiate male and female through dry skulls, using the measurement of the Radiocef Studio 2 Program. It was used 16 teleradiographs (11 females and 5 males). The linear measurements used in this article were: 1. The bodies stature of the mandible; and 2. Distance Nasium-Front Nasal Spine. Several radiological techniques are used to aid the human identification process for determining sex, ethnic group, and age. The analyses of X-rays and Computer Tomography (CT) scans, antemortem and postmortem, have been an important tool for human identification in forensic dentistry, especially with the refinement of techniques acquired with the advancement of radiology and CT scans. We concluded that the knowledge of the best method by forensic dentists with a careful application of the technique and report's interpretation is essential to fulfilling the necessary characteristics for a successful identification of sex using skull measures. Keywords: Radiology. Forensic Dentistry. Sex. Cranial Measures.

The human identity is the set of own and exclusive characters of a person: physical, functional, psychic, born or acquired, such as name, age, state, profession, sex, physical defects, fingerprints. Thus, the identity could be defined as the collective aspect of a set of characteristics by which something is recognizable or known [1].

Identification is the process by which one determines the identity of a person or a thing [2]. Personal identification is essential in Forensic Medicine.

Establishing postmortem human identity is one of the significant areas of study and research in dentistry and legal medicine. These forensic sciences study the human body in various stages of postmortem: sprung, torn, charred, macerated, decomposed, and skeletonization.

Received on 20 February 2019; revised 4 March 2019.

Address for correspondence: Dr. Alile Fixina do Carmo. Avenida $60 \mathrm{Dr}^{\circ}$ Antonio Monteiro Street, Apt. \# 502, Zip Code: 41815-130, Salvador, Bahia, Brazil, phone: +55 71 988960093; e-mail: afcarmo76@gmail.com.

J Bioeng. Biotech. Appl. Health 2019;2(2):54-58.

(C) 2019 by SENAI CIMATEC. All rights reserved.
Some methods used for identification include fingerprints, anthropological and radiological examinations, genetic analysis (DNA), and dental analysis (especially in carbonization cases).

The process of human identification by radiographic comparison is a technique little used in Legal Medicine, despite presents a satisfactory and unquestionable results.

The participation of dentistry in the processes of postmortem human identification is present since the initial procedures (general identification: estimates of sex and age, ethnic group determinations, stature, diagnosis of spots or liquids in the oral cavity, definition of cause and time of death) until the irrefutable possibility of the individual identification. The skull and teeth assume relevant identification in situations of substantial destruction of the human body (spoils, fragments, bony or carbonized mortal remains) because of the higher resistance when compared to the other structures. The skull and teeth are often the only elements from which identity can be derived: race, age, stature, and sex. 
The human skeleton of children and preteenager has qualitative characteristics little pronounced, providing few or no subsidy to make possible the identification of sex. In these cases, it is required other methods to determine sex, such as DNA, sexual chromatin, or teeth. [3].

The human skeleton develops after puberty under the influence of hormones, environment, and musculature, presenting differential characteristics, such as prominences, roughness, crests, apophyses, protrusions, and structures that characterize the sexual dimorphisms.

These characteristics are more prominent and evident in men than in women, in which these characteristics are more delicate and less prominent.

Ramirez (1990) [4] defines the male skull as larger than the female, which is more rounded, childlike. The frontal bone is more upright, and the parietal is smaller; the supraorbital ridges are sharp; the superciliary arches are less protruding; the front nasal joint is more curved; the styloid apophyses are short and thin; there are occipital protuberance and unmarked necklines; the mastoid processes are smaller; the occipital condyles are broad, short, and the jawless are robust. In man, the cranial thickness is greater; the forehead tilted back; the parietal bones are larger; the glabella is prominent; the superciliary arcs are protruding; the ridges above the blunt orbital; the frontal-nasal joint is angular; the styloid apophyses are long and thick; the mastoid processes are protruding and separated (sole shoe shape); the prominent occipital protuberance and regions of muscle insertions, and the more robust jaw. The palate has a broad and shallow form in males, different from females in which it is narrower and more profound, having thinner dental arches.

The bones that form the basin and the skull have reliable characters for determining sex. However, the degree of certainty of the diagnosis varies according to the number and nature of the parts examined. For example, the ethnic group should be known to identify the sex, due to the characteristics of each group.
Nowadays, the sexual difference has been studied under metrical parameters, transforming physical and qualitative characteristics into numerical values that, submitted to statistical analysis, derive metrical relations or discriminant functions. This analysis is endowed with single or multiple variables from the same measurement bone or from various structures, depending on the population that the data were collected [5-7].

In specific populations, the use of computers and mathematical models provide more reliable and accurate results in sexual determination [8,9].

Abe (2000) [6] apud Inoue et al. (1992) agree that these models enable a less experienced examiner to discriminate sex as precisely as an experienced observer. However, the statistical analysis does not replace the experts, since their competence is essential to avoid errors.

Historically, the application of radiology in the forensic sciences was introduced in 1896, just one year after X-rays were discovered by Roentgen to demonstrate the presence of lead bullets in a victim's head. Schüller proposed the possibility of using radiological images of the facial sinuses for identification purposes in 1921.

Galvão and Vitória [11] studied skulls of the Brazilian population, belonging to individuals of known sex and age group over 20 years in 1994. They concluded that the dimensions of the foramen magnum are larger in men than in women.

Saliba [12], in 2001, carried out a study of sex determination through the area formed by the triangle of the upper face, using 168 dry skulls of adult humans, over 20 years. After analysis, the Nasium-Anterior Nasal Spine (N-Ena) measure was 57.15 to 60.06 for female and 61.25 to 63.68 for male.

The present work chooses for a more precise and rational mathematical method for sex determination and aims to compare the measures obtained by the study models of Galvão (1994) and Saliba (2001), with the criteria acquired, using the measurement performed in lateral teleradiography by the following linear measurements of the cranium: 1. Height of the mandible body and 2 . 
Nasium-Anterior Nasal Spine by the program Radiocef Studio 02. Therefore, we proposed:

1. To verify the existence of sexual dimorphism using two linear measurements, performed by the program Radiocef Studio 2, in lateral teleradiography, belonging to individuals of known sex;

2. To check the degree of correctness of the values found in dry skulls, in the studies surveyed, with the radiographic values obtained.

The sample consisted of lateral cephalometric radiographs of 16 individuals (11 female and 5 male), without previous orthodontic treatment and without presenting moderate to advanced bone loss. The IOBA Clinic provided the samples' data. All the individuals showed balanced facial profiles and absence of retrognathia or prognathia of the bone bases and typical vertical pattern. All radiographs were performed on the same Orthophos Panoramic X-ray apparatus from Siemens, with the same distance and intensity. The procedure was carried out by a single examiner to avoid discrepancies between the measures obtained. The values analysed were obtained by marking the points Nasium (N), Mental (Me), Infradental (Id) and Anterior Nasal Spine (Ena) by the program Radiocef Studio 02 and the measurement of the following linear measures: height of the mandible body (Id-Me) and distance Nasium-Anterior Nasal Spine (N-Ena) (Figure 1).

These values were compared with those found in the researched literature. For the height of the mandible body, the values used as parameters were those found by Galvão in 1994 [11] (Table1). The study of Saliba (2001) [12] was used for the previous Nasium -Anterior Nasal Spine measure, considering this study presented statistically significant differences for the confirmation of sexual dimorphism, in agreement with earlier studies - Peixoto (1931) [13] and Ávila (1958) [14] (Table 2).

We compared the authors, and it showed that the mandible body height (Id - Me) for the measurement in millimeters, when compared both sex, had a compatibility of $27.27 \%$, with the values found by Galvão [11] in 1994 for females; and $100 \%$ for males (Table 3 ). There was an agreement with $81.81 \%$ to female and $80 \%$ for the male when compared the distance Nasium-Anterior Nasal Spine (N-Ena) in millimeter, with the study of Saliba (2001) [12] (Table 3). According to the proposed comparison and applied methodology, we conclude that:

1. Linear Nose-Spine (N-Ena) measurements, considered as acquired in human skull belonging to known sex, showed compatibility with Saliba (2001) [12] for sexual differentiation;

2. For the measurement Height of the mandible body (Id-Me), in the same study, a concordance of $27.27 \%$ was found with the values found by Galvão (1994) [11] for the female sex, and $100 \%$ of compatibility for males;

3. Among the two measures analysed, the NasiumAnterior Nasal Spine (N-Ena) measurement demonstrated more excellent reliability in the obtained results.

Due to the variety of methods available, the legal dentistry professional can choose the method that best fills the characteristics necessary for the success in the sex identification, taking care in the correct application of the technique and the accurate interpretation of the results.

\section{Acknowledgements}

We would like to thank CIMATEC, Federal University of Bahia (UFBA) (School of Odontology, Department of Radiology) and clinic IOBA for all support in the development of this study.

\section{References}

1. Ferreira, A.B.H. Mini Aurélio século XXI - O minidicionário da língua portuguesa. Rio de Janeiro: Nova Fronteira, 2004;(5).

2. França, G.V. Medicina Legal. Rio de Janeiro: Guanabara Koogan, 2004;(7).

3. Duz, S.A. Determinação do sexo através da cromatina sexual na polpa dentária e sua importância pericial [dissertação]. Piracicaba: UNICAMP/FOP, 2000. 
Figure 1. Cephalometric points and linear measurements of the skull.

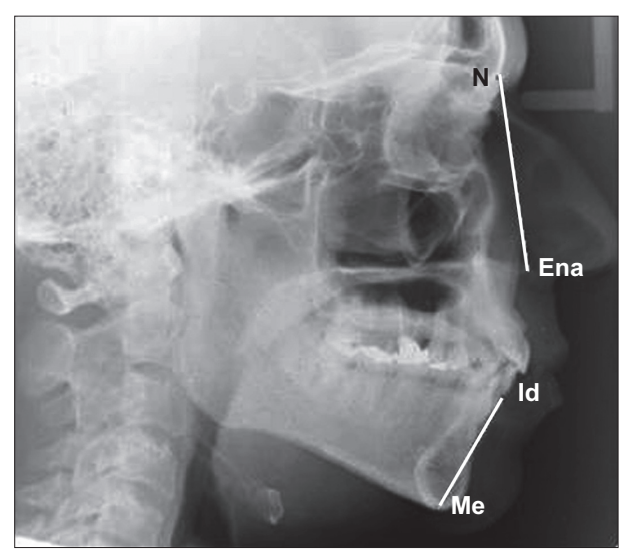

Table 1. Parameter height of the mandible body (Id-Me) were found by Galvão (1994) [11].

\begin{tabular}{lrrrrr}
\hline & \multicolumn{2}{c}{ Male } & \multicolumn{2}{c}{ Female } \\
\cline { 2 - 3 } Parameter & Confidence & Probable & Undetermined & Confidence & Probable \\
$\begin{array}{l}\text { Height of the mandible body } \\
(\text { Id-Me) }(\mathrm{mm})\end{array}$ & $>41.00$ & $33.50-41.00$ & $31.00-55.50$ & $<27.00$ & $27.00-31.00$ \\
\hline
\end{tabular}

Table 2. Nasium-anterior nasal spine measure by Saliba (2001) [12].

\begin{tabular}{lccc}
\hline & Minimum & Normal & Maximum \\
\hline Female & $57.15 \mathrm{~mm}$ & $58.61 \mathrm{~mm}$ & $60.06 \mathrm{~mm}$ \\
Male & $61.25 \mathrm{~mm}$ & $62.56 \mathrm{~mm}$ & $63.68 \mathrm{~mm}$ \\
\hline
\end{tabular}

Table 3. Data result.

\begin{tabular}{ccccc}
\hline Sample & $\begin{array}{c}\text { Sex } \\
\text { (Id-Me) }\end{array}$ & $\begin{array}{c}\text { Body height of the jaw } \\
\text { (N-Ena) }\end{array}$ & $\begin{array}{c}\text { Distance nasium-anterior } \\
\text { nasal spine }\end{array}$ & City \\
\hline 1 & $\mathrm{~F}$ & $32.81 \mathrm{~mm}$ & $53.22 \mathrm{~mm}$ & Salvador \\
2 & $\mathrm{~F}$ & $29.12 \mathrm{~mm}$ & $50.55 \mathrm{~mm}$ & Salvador \\
3 & $\mathrm{~F}$ & $28.69 \mathrm{~mm}$ & $57.40 \mathrm{~mm}$ & Salvador \\
4 & $\mathrm{~F}$ & $38.70 \mathrm{~mm}$ & $57.19 \mathrm{~mm}$ & Salvador \\
5 & $\mathrm{~F}$ & $30.89 \mathrm{~mm}$ & $44.97 \mathrm{~mm}$ & Salvador \\
6 & $\mathrm{~F}$ & $39.94 \mathrm{~mm}$ & $57.93 \mathrm{~mm}$ & Salvador \\
7 & $\mathrm{~F}$ & $39.36 \mathrm{~mm}$ & $60.41 \mathrm{~mm}$ & Salvador \\
8 & $\mathrm{~F}$ & $35.01 \mathrm{~mm}$ & $57.45 \mathrm{~mm}$ & Salvador \\
9 & $\mathrm{~F}$ & $39.44 \mathrm{~mm}$ & $59.95 \mathrm{~mm}$ & Salvador \\
10 & $\mathrm{~F}$ & $36.04 \mathrm{~mm}$ & $59.40 \mathrm{~mm}$ & Salvador \\
11 & $\mathrm{~F}$ & $32.62 \mathrm{~mm}$ & $59,92 \mathrm{~mm}$ & Salvador \\
12 & $\mathrm{M}$ & $40.82 \mathrm{~mm}$ & $61.61 \mathrm{~mm}$ & Salvador \\
13 & $\mathrm{M}$ & $36.55 \mathrm{~mm}$ & $63.37 \mathrm{~mm}$ & Salvador \\
14 & $\mathrm{M}$ & $37.99 \mathrm{~mm}$ & $56.18 \mathrm{~mm}$ & Salvador \\
15 & $\mathrm{M}$ & $34.04 \mathrm{~mm}$ & $61.31 \mathrm{~mm}$ & Salvador \\
16 & $\mathrm{M}$ & $41.00 \mathrm{~mm}$ & $63.39 \mathrm{~mm}$ & Salvador \\
\hline
\end{tabular}


4. Francesquini, M.A. Dimorfismo sexual por medidas da face e base do crânio e sua importância pericial. Dissertação de Mestrado-Faculdade de Odontologia de Piracicaba-UNICAMP, 2001, São Paulo.

5. Ramirez, A.I.C. Identificacion Forense. México: Trillas, 1990;(1):19-22.

6. Abe, D.M. Avaliação do sexo por análise de função discriminante a partir de dimensões lineares do cranio. Tese de Mestrado-Faculdade de Odontologia de Piracicaba-UNICAMP, 2000, São Paulo.

7. Carvalho, S.P. M. A utilização de imagens na identificação humana em Odontologia Legal. Radiologia Brasileira, 2009; 42(2):125-30.
8. Galvão, L.C.C., Vitória, E.M. Investigação do sexo através do forame magno. [Apostila]. Salvador: Universidade Federal da Bahia, 1994.

9. Saliba, T.A. Determinação do sexo através da área formada pelo triângulo da face superior. Tese de DoutoradoFaculdade de Odontologia de Piracicaba-UNICAMP, 2001, São Paulo.

10. Galvão, L.C.C. Identificação do sexo através de medidas cranianas. Tese de Mestrado-Faculdade de Odontologia de Piracicaba-UNICAMP, 1994, São Paulo.

11. Peixoto, A. Medicina Legal, São Paulo: F. Alves,1931;(6):363.

12. Ávila, J.B. Antropologia Física. Rio de Janeiro: Agir. $1958 ; 138$. 


\title{
Liposome Drug Delivery in Cancer Chemotherapy: Review and Multifactorial Analysis
}

\author{
Tatiara Régis ${ }^{1 *}$; Luciana Knop²; Bruna Machado²; Valter de Senna ${ }^{3}$ \\ ${ }^{1}$ SENAI CIMATEC, Doctorate Computational Modelling and Industrial Technology; ${ }^{2}$ SENAI CIMATEC, Technology \\ Institute of Health; ${ }^{3}$ SENAI CIMATEC, Computational Modelling and Industrial Technology; Salvador, Bahia, Brazil
}

\begin{abstract}
We reviewed the use of liposomes for cancer therapy using computational biostatistics. We used virtual libraries, such as PubMed, LILACS, National Health Institute (NHI) and the Food Drug Administration (FDA) to conduct the review. Cluster analysis and correlation were developed using the Tanimoto coefficient (TC) of 0.7 using the modeling tool ChemMine Tools from databases (PubChem, DailyMed, DrugBank, Drug @ FDA). The results pointed fifteen molecules in the pharmaceutical form of liposome for the oncological clinic. Of these, 13 are classified by size into small-molecules and were analyzed by computational statistical modeling. Of these, only 4 were approved for use by the FDA, and 9 are in phases of research by the pharmaceutical industry as liposomal formulations. Essential differences in physical-chemical properties and molecules structure were observed, indicating original proposal in the development of liposomal as an anticancer drugs.
\end{abstract}

Keywords: Bioinformatics. Cancer. Drug delivery. Liposomal.

The cancers have in common the disordered and malignant growth of several cell lines with the capacity to invade other tissues far from the place of origin, forming secondary tumors or metastases [1]. The disease is currently one of the world's public severe health problems. According to Globocan 2018, a project by the International Agency for Research on Cancer (IARC) of the World Health Organization (WHO), there were 14.7 million new cases of cancer and a total of 9.8 million cancer deaths worldwide in 2018, and a projection of almost 21.4 million new cases until 2030 with 13.2 million cancer deaths [2].

So, new antitumoral drugs are in tests as well as new methods to deliver these drugs. Due to the limitations and toxic events of conventional chemotherapies, several nanocarrier delivery systems have been developed and extensively used for drug delivery to cancer cells [3-5]. A large number of nanocarriers such as liposomes, polymeric nanoparticles, micelles, nanotubes, are already in the market, or under research and

Received on 17 February 2019; revised 23 February 2019. Address for correspondence: Dr. Tatiara Regis. Avenida Orlando Gomes, N. 1845, Piatã, Zip code: 41.650-010; Salvador, Bahia, Brazil. E-mail: tatiararegis3@gmail.com.

J Bioeng. Biotech. Appl. Health 2019;2(2):59-69.

(C) 2019 by SENAI CIMATEC. All rights reserved. evaluation for cancer treatment [6]. Reports reveal an estimated global growth of liposome drug delivery (LDD) around $\$ 3.6$ billion by 2020 in the global economic market and pharma industry [7].

The structural diversity and encapsulated drugs, as well as the mechanics of action liposomes, created a new technological perspective. However, there are challenges in methods for the preparation of liposomes, methods for efficient drug delivery, and procedures for the entrapment the drugs in the liposome. So, the innovations in liposome technology target researching that make it possible to predict new formulations and drugs for antitumoral treatments.

This review summarizes the types of methods used for the preparation of liposomes, mechanism of drug loading and potential therapeutic applications in cancer therapy, and provide current information on the liposomal products as a potent anticancer delivery drugs, either in clinical use or in clinical trials.

\section{Liposomes}

Liposomes have been widely used for several therapeutic applications, primarily as delivery drugs to reduce the toxic effects in the standard cell. They have also been used to optimize the bioavailability 
of drugs in areas such as pharmacology, oncology, cell biology, immunology, genetic engineering, and therapeutic and preventive medicine.

Liposomes have a larger surface area as compared to bigger particles, which can be easily modified to encapsulate a high amount of drug, increasing the blood circulation time, and enhancing the accumulation of drugs in solid tumors by permeability and retention (EPR) effect as well as selective targeting of tumor cells [8-10]. They also improve the solubility, bioavailability and pharmacokinetic properties of chemotherapeutics $[9,11,12]$.

Liposomes have an unusual sphere structure, globular lipid bilayers of 50-1,000 nm. They are versatile, notably in size, surface charge and have phospholipid bilayer membranes similar to plasmatic membranes, which favored the permeability of the molecules to get into the cell [13]. Therefore, these structures can encapsulate and deliver both hydrophilic and hydrophobic substances.

\section{Drug Delivery Systems (DDS)}

DDS are methods of administering drugs to reduce side effects and increase therapeutic efficacy, such as reduction of toxicity for anticancer agents [7,13]. DDS represents an advance in pharmaceutical technology compound to achieve a therapeutic effect in drug delivery for several treatments $[13,14]$.

Liposomes are a potential DDS [15] (Figure 1). For example, niosome are non-ionic surfactant vesicles obtained on hydration of synthetic nonionic surfactants, with or without incorporation of cholesterol or their lipids [16] by sub-micron (colloidal) of types MLVs (size $\geq 0.05 \mu \mathrm{m}$ ), LUVs ( size $\geq 0.10 \mu \mathrm{m})$, SUVs ( size $=0.025-0.05 \mu \mathrm{m})$ [17], and consist of advanced DDS liposome (Figure 2) [18].

Gregoriadis and colleagues [19] consider two aspects that justify the promising future of liposomes drug delivery (LDD): reducing toxic side effects, and incoming of the drug in tumor cells. The studies by liposomes have been showing that the absorption of the drug by tumor cells is superior to drugs used in chemotherapies [20].

\section{Designing Liposomes Drug Delivery (LDD)}

The physicochemicalproperties of the liposomes are generally useful for characterizing a drug formulation, which must be more stable to avoid changes in product quality, including leakage of the drug. So, chemical, manufacturing and control (CMC); pharmacokinetics and bioavailability; and labeling documentation for liposome products submitted to new drug applications (NDAs) and abbreviated to new drugs (ANDAs) have been reviewed by the Center for Drug Evaluation and Research (CDER) [21] and recommended by the FDA for Industry.

The production of liposomes involves the use of an active agent and a phase lipid/lipid drug. So, the variety of natural or synthetic lipids, the different sizes, and molar rays, lead to a diversity of liposomes. In this aspect, the inherent properties of the carriers' structures and the nature of the drug to be encapsulated could affect biological half-life and modify drug absorption due to the relation between such structures and physicochemical characteristics of the drug substance (Table 1) [22].

At present, the designing stage of the liposome is still in the beginning. So, the choice of the

Figure 1. Illustration of liposome for drug delivery.

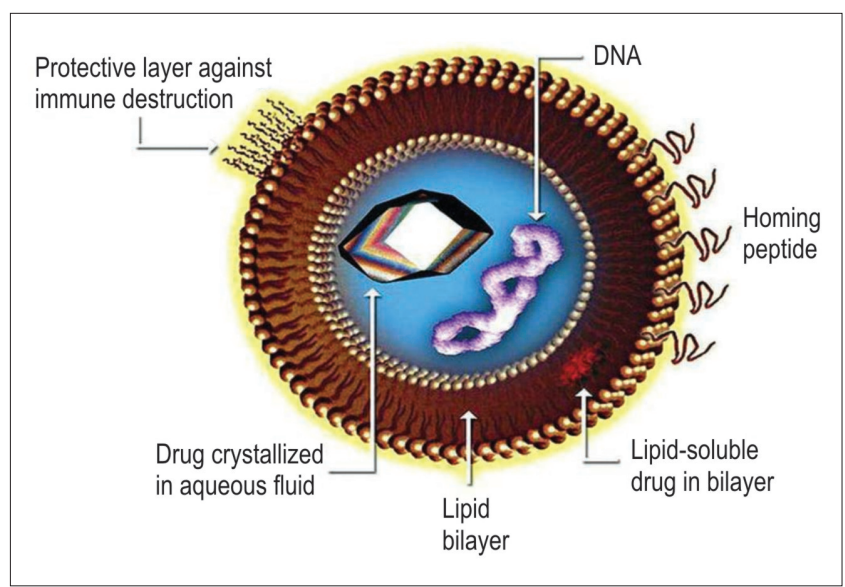

Source: Çağdaş M. et al. (2010) [15]. 
Figure 2. A schematic structures of non-ionic surfactant vesicle.

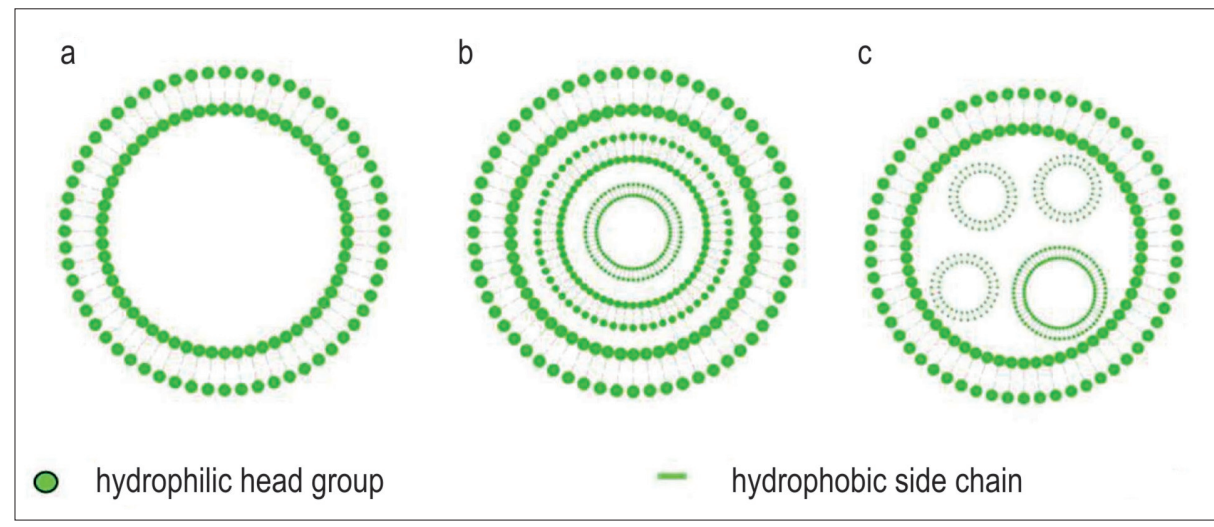

(a) unilamellar vesicle, (b,c). multi-lamellar vesicle [18].

best liposome design and reagent quality may be decisive for the testing phases for drug approval.

\section{Liposomes Drug Delivery in Cancer}

FDA approvals 16 news therapies for cancer with new pharmaceuticals, including new molecular entities (NMEs) and new Biologic License Applications (BLAs) between 20132016. The pipeline of 836 drugs for cancer using liposomes in 2016, 123 were for lung cancer, 106 for leukemia, 92 for lymphoma (including nonHodgkin lymphoma), 82 for breast cancer, 58 for brain tumors, 53 for skin cancer (including melanoma) [23].

According to Institute for Healthcare Informatics (IMS) on Global Use of Drugs [24], many potential applications of liposomes in immunotherapies and targeted therapies will be a promising field in oncology and drug delivery in 2020 [25].
Regarding clinically used liposome-based products in cancer chemotherapy active agent indicated for the treatment of different types of cancer are Doxorubicin (DOX) (Doxil@/ Myocet ${ }^{\circledR}$ ), Daunorubicin (DAU) (DaunoXome ${ }^{\circledR}$ ), Cytarabine/Ara-C (Depocyt $\left.{ }^{\circledR}\right), \quad$ Mifamurtide (Mepact $\left.{ }^{\circledR}\right)$, Vincristine (Marqibo () , Irinotecan (Onivyde ${ }^{\mathrm{TM}}$ ). Also, the pharmaceutical industry is testing for some new active substance (NAS) Tecemotide, T4 endonuclease V, Cisplatin, Lurtotecan, Paclitaxel, all-trans retinoic acid for treating different types of cancer [26]. For example, Idarubicin (IDA), a drug exclusively used for the treatment of leukemia through thermosensitive liposomes (TSL) in combination with hyperthermia (HT) demonstrated to be more prominent tumor growth inhibition in leukemia than in the conventional form [27].

Some of these drugs have already in Phase II in Japan, as Stimuvax ${ }^{\circledR}$ (Tecemotide/L-BPL

Table 1. Effect of the nature of the drug on the formation of niosomes.

\begin{tabular}{llll}
\hline Nature of drug & Leakage from the vesicle & Stability & Oher properties \\
\hline Hydrophobic drug & Decreased & Increased & Improved transdermal delivery \\
Hydrophilic drug & Increased & Decreased & - \\
Amphiphilic drug & Decreased & - & $\begin{array}{l}\text { Increased encapsulation, } \\
\text { altered electrophoretic mobility }\end{array}$ \\
& & & - \\
\hline
\end{tabular}

Modified from KM Kazi et al. (2010) [22]. 
25) [28]: a liposome vaccine against the cancer cells that overexpress Mucin 1 (MUC-1) (Figure 3 ), a glycoprotein antigen expressed in cancers such as multiple myeloma and colorectal, breast cancer, prostate and ovarian cancers. However, the results of Stimuvax ${ }^{\circledR}$ were disappointing to the investigational therapeutic vaccine to enter Phase III (PhIII) studies in Non-Small Cell Lung Cancer (NSCLC), mainly due to flops in Phase III lung cancer trial and breast tumors [28-30]. Even so, the pharmaceutical company, Merck, will be responsible for the clinical development, commercial producing and marketing, estimated the sales to reach about $€ 350 \mathrm{~m}$ in 2019 [28].

Pfizer developed and produced the drug Xalkori ${ }^{\circledR}$ (Crizotinib) [31] for the treatment for Non-Small Cell Lung Cancer (NSCLC) and metastatic anaplastic lymphoma kinase (ALK) approved by FDA in August 2011 using liposomes [32]. Crizotinib is a receptor tyrosine kinase inhibitor that inhibits ALK and c-MET, and it is also been using in a liposome as a targetantitumoral drug [33,34].

Darolutamide by Bayer and Orion [33] have reported positive results in Phase III clinical trial (ARAMIS) in patients with non-metastatic castration-resistant prostate cancer using liposomes [35].
Avapritinib, an inhibitor of KIT and PDGFR $\alpha$ $\mathrm{D} 842 \mathrm{~V}$ mutant kinases, is under clinical development in China at present (2019) for GI Stromal tumors $[33,36]$.

Analysis of Liposome Drug Delivery in Anticancer Therapy

We performed a database of chemical molecules, substances, compounds, bioassay, drugs and drugs for therapeutic or clinical medicine in liposomes using (PubChem) (National Institutes of Health - NIH), DailyMed [37], DrugBank [38,39], Drug@FDA [40], Pubmed (Medline), Cochrane Foundation, Isi Web of Science. Our focus was to find molecular similarities and correspondence for both liposome drug and drug delivery molecule for anticancer therapies, both approved and already in use, as well as those that are released by the FDA for in phases 3,2,1 or investigative research.

Fifteen molecules were found in the pharmaceutical form of liposome for oncological clinic. Of these, 13 are classified by size into smallmolecules and were analyzed by computational statistical modeling. Of these only four were approved for use by the FDA, and nine are in phases of research by the pharmaceutical industry as liposomal formulations (Table 2). Tecemotide (Stimuvax $\left.{ }^{\circledR}\right)$, Vincristine (Marquibo $\left.{ }^{\circledR}\right)$, and

Figure 3. Proposed mode of action of L-BPL 25.

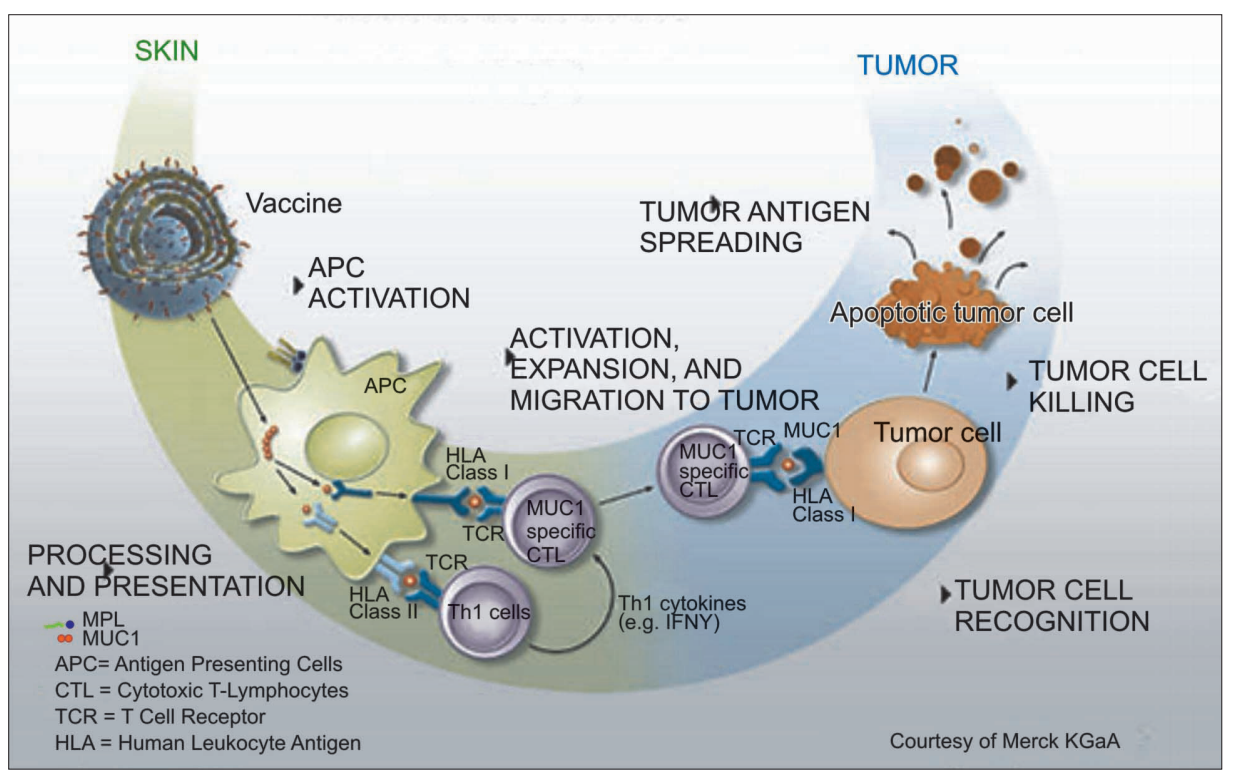


Table 2. Therapy and anticancer LDD approved by FDA and in investigative research.

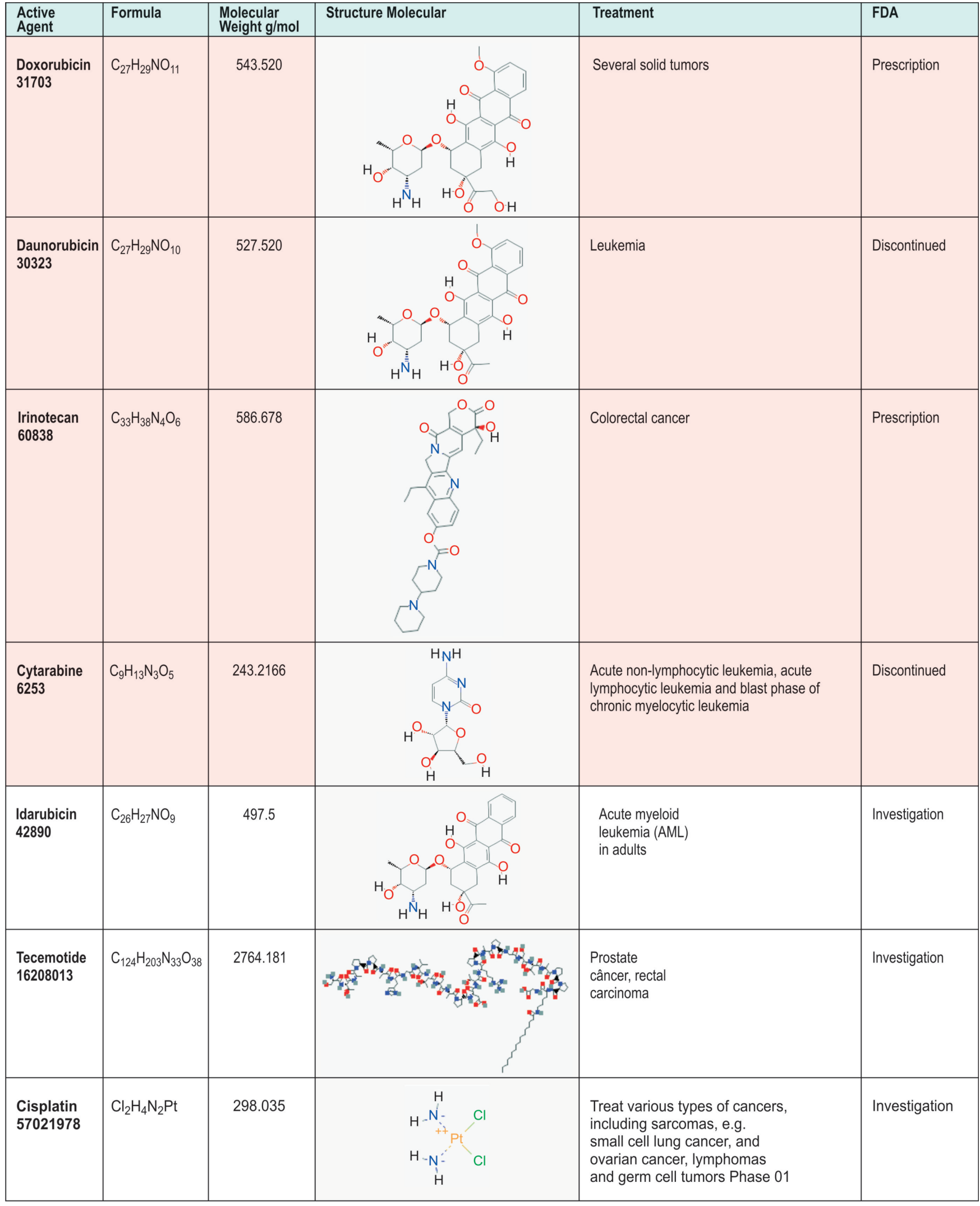

The pink's lines is active agent approved FDA and used liposome-based products for treatment various types of cancer. 


\section{(continued Table 2)}

\begin{tabular}{|c|c|c|c|c|c|}
\hline $\begin{array}{l}\text { Active } \\
\text { Agent }\end{array}$ & Formula & $\begin{array}{l}\text { Molecular } \\
\text { Weight } \mathrm{g} / \mathrm{mol}\end{array}$ & Structure Molecular & Treatment & FDA \\
\hline $\begin{array}{l}\text { Lurtotecan } \\
60956\end{array}$ & $\mathrm{C}_{28} \mathrm{H}_{30} \mathrm{~N}_{406}$ & 518.57 & & $\begin{array}{l}\text { Antineoplastic } \\
\text { activity }\end{array}$ & $\begin{array}{l}\text { Investigation / } \\
\text { BioAssay }\end{array}$ \\
\hline $\begin{array}{l}\text { Paclitaxel } \\
36314\end{array}$ & $\mathrm{C}_{47} \mathrm{H}_{51} \mathrm{NO}_{14}$ & 853.918 & & $\begin{array}{l}\text { Carcinoma of the ovary, and other } \\
\text { various cancers including } \\
\text { breast cancer }\end{array}$ & $\begin{array}{l}\text { Investigation } \\
\text { for liposome } \\
\text { form }\end{array}$ \\
\hline $\begin{array}{l}\text { All-trans Acid } \\
\text { Retinoic } \\
444795\end{array}$ & $\mathrm{C}_{20} \mathrm{H}_{28} \mathrm{O}_{2}$ & 300.442 & & Acute promyelocytic leukemia (APL) & Investigation \\
\hline $\begin{array}{l}\text { Crizotinib } \\
11626560\end{array}$ & $\mathrm{C}_{21} \mathrm{H}_{22} \mathrm{Cl}_{2} \mathrm{FN}_{5}$ & 450.339 & & Non-small cell lung cancer & Prescribed \\
\hline $\begin{array}{l}\text { Darolutamide } \\
67171867\end{array}$ & $\mathrm{C}_{19} \mathrm{H}_{19} \mathrm{ClN}_{6} \mathrm{O}_{2}$ & 398.851 & & Prostate câncer & Descontinued \\
\hline $\begin{array}{l}\text { Avapritinib } \\
118023034\end{array}$ & $\mathrm{C}_{26} \mathrm{H}_{27} \mathrm{FN}_{10}$ & 498.57 & & & Investigation \\
\hline
\end{tabular}


Mifamurtide (Mepact $\left.{ }^{\circledR}\right)$ were not evaluated in this analysis.

We use ChemMine ${ }^{\circledR}$ for small molecules data analysis relevant in chemical biology, chemical genomics, and drug discovery [41]. ChemMine ${ }^{\circledR}$ proved to be an excellent software to study similarity, clustering, prediction of a small molecule, integrating the physicochemical and bioactivity properties through PubMed [42].

Few similarities are found between the liposome-based products in Cancer Chemotherapy approved (Graphic 1). So, the diversity physicochemical characteristics of a drug molecule in terms of therapeutic class and chemical structures, involving different functional groups are factors considered essential to meet FDA recommendations about liposomes as a tool with anticancer drugs.

The graphics multidimensional scaling(MDS) is an array of item distances. The coordinates are assigned to each item in a low-dimensional space to represent the distances graphically in a scatter plot.

The distance matrices required for the clustering of MDS were calculated by comparisons of all against all compounds using measures of similarity of atom pairs, the similarity of substructures and transforming similarity scores generated in distance values. According to the model proposed by ChemMine $\AA$, basic descriptor type that is defined by the shortest paths among the non-hydrogen atoms in a molecule are atom pair. The TC calculated the similarity and the distance values were calculated by subtraction $(1-T c)$. Then, the coordinates are assigned to each item in a low-dimensional space to plot the distances in a scatter plot. We determined $\mathrm{Tc}=0.7$. The coefficient varies between $0-1$, the higher, the greater, and the greater the similarity. The axes V1 and V2 represent the chemical space in two directions. A higher correlation between the structures contained in the pink band on Graphic 2 .
HC results were developed based on the molecular weight and physicochemical properties heat map Joe Lib descriptors. The JOELib tool computes 38 descriptors for each compound. The result showed the most similar of all molecular, almost identical is cluster hierarchical formed by DOX/ DAU and IDA. IDA is closer in physicochemical properties of DAU than dox. DAU has been discontinued for economic issues unrelated to the product's quality, safety or efficacy.

Boron (B), Bromine (B), Iodine (I), Phosphorus (P), Sulfur (S), SO2, -SO2, -OSO, $-\mathrm{NO} 2$, and hydrophilic groups are not present in all active agents.

The molecular weight, an import characteristic for liposome development varies in green range by almost all molecules, except Cytarabine, All-trans- Acid retinoic, Darulutamide and Paclitaxel.

Several halogen atoms are down (blue for green), but more in the cluster formed by Crizotinib, Daurulutamide, and Avapritinib.

The number of primary groups and acid groups between the active agents, Lurtotecan showed the most significant amount of basics groups. However, with the predominance of acid groups, eight of the fifteen compounds analyzed contained more acid groups, highlighting all trans-acid-retinoic.

Lurtotecan and Irinotecan were outside the correlation range due to out of the correlation range due to the presence of a primary group in the first and greatest geometrical diameter in second. On the other hand, Cytarabinestands out from all other compounds by having lower: molecular weight, P-hydroxybenzaldehyde, heavy bonds, number of atoms, number of bonds, geometrical diameter, and other descriptors.

\section{Conclusion}

The use of liposome as anticancer therapy is restricted. However, liposomes are an essential research niche for NAS prospecting 
Graphic 1. Multidimensional Scaling Clustering (MDS) of the NAS liposome in clinical oncology.

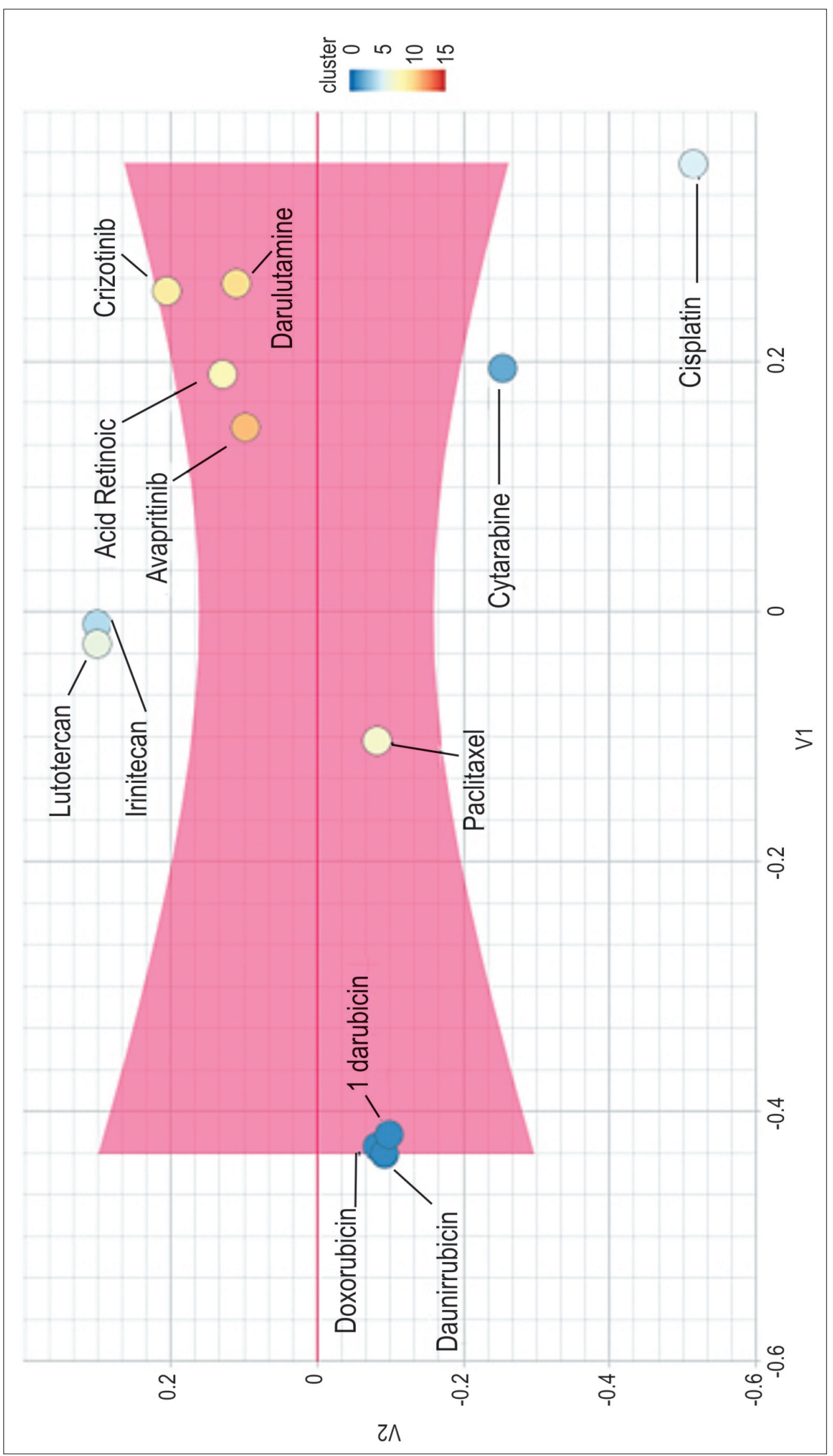


Graphic 2. Hierarchical Clustering Results of the NAS liposome in clinical oncology.

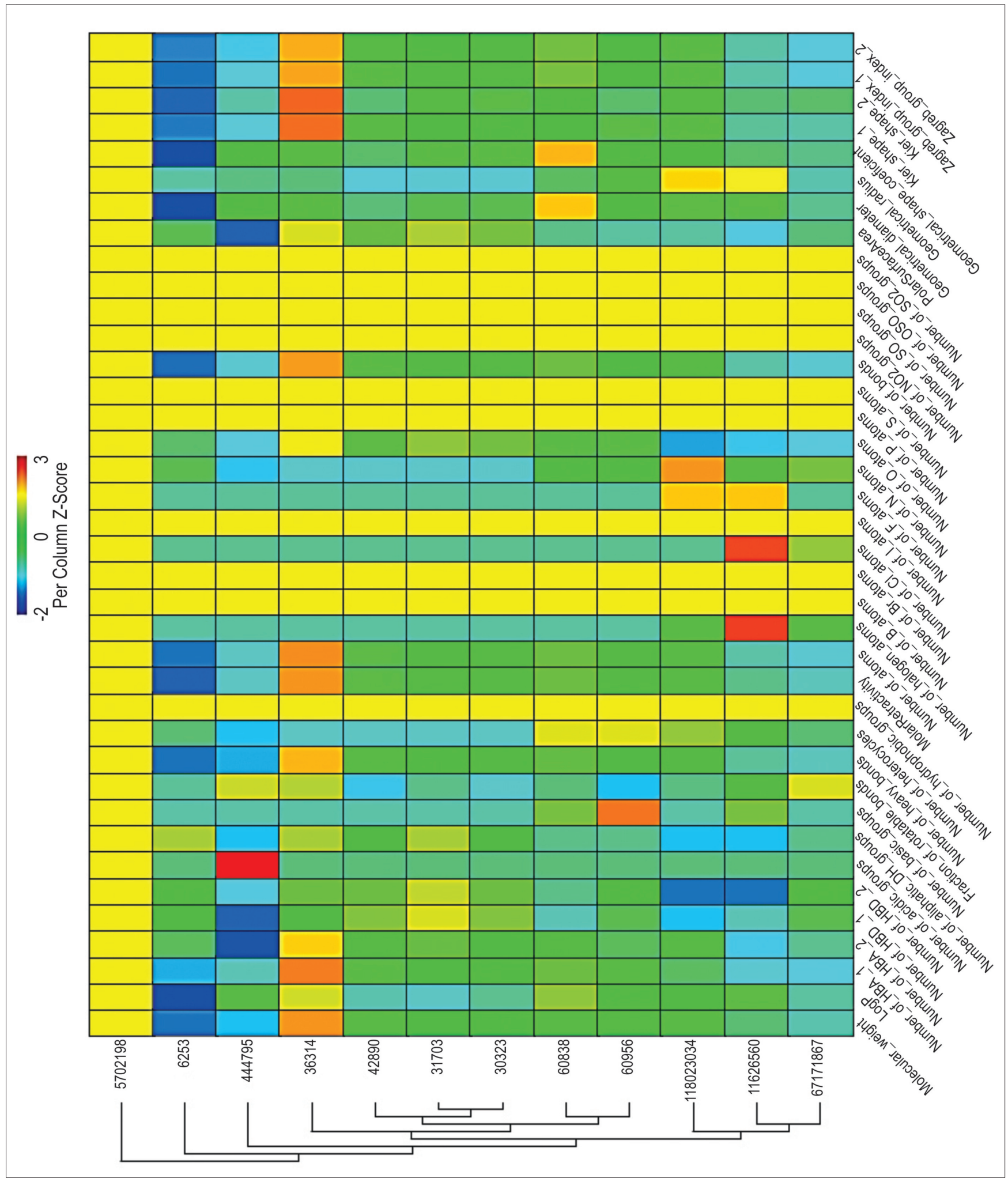


in which the evaluation of the physical and chemical characteristics of the pharmaceutical by computational methods can provide valuable information for the development of LDD in antineoplastic therapy. Nevertheless, it is essential to make a point of time-based understanding of physicochemical and bioactivity properties may be useful in finding methods of predicting more assertive experimental bed paths.

\section{References}

1. INCA. Estimativa do câncer para 2017. Boletim. Disponível em: www.inca.gov.br. Acessado em 26 de março de 2017.

2. Globocan 2018 v1.0, Cancer Incidence and Mortality Worldwide: IARC Cancer Base No. 11 [Internet]. Lyon, France: International Agency for Research on Cancer; 2016. Available from: http://globocan.iarc.fr, accessed on $10 / 06 / 2018$.

3. Tyagi, N., Ghosh, P.C. Folate receptor mediated targeted delivery of ricin entrapped into sterically stabilized liposomes to human epidermoid carcinoma (KB) cells: effect of monensin intercalated into folate-tagged liposomes. Eur J Pharm Sci. 2011;43:343-53.

4. Tyagi, N., Rathore, S.S., Ghosh, P.C. Enhanced killing of human epidermoid carcinoma (KB) cells by treatment with ricin encapsulated into sterically stabilized liposomes in combination with monensin. Drug Deliv. 2011;18:394-404.

5. Arora, S., Tyagi N., Bhardwaj, A. et al. Silver nanoparticles protect human keratinocytes against UVB radiation-induced DNA damage and apoptosis: potential for prevention of skin carcinogenesis. Nanomedicine. 2015;11:1265-75.

6. Sutradhar, K.B., Lutful, A. Nanotechnology in Cancer Drug Delivery and Selective Targeting. ISRN Nanotech. 2014: 939378. doi: 10.1155/2014/939378.

7. NHI National Institute of Biomedical Imaging and Bioengineering. About: Drug Delivery Systems. Website: NHI National Institute of Biomedical Imaging and Bioengineering, October 2016. Disponivel em: $<$ https://www.nibib.nih.gov/science-education/sciencetopics/drug-delivery-systems $>$. Acesso em: 19 Feb 2019.

8. Tyagi $\mathrm{N}$ and Ghosh PC. Folate receptor mediated targeted delivery of ricin entrapped into sterically stabilized liposomes to human epidermoid carcinoma (KB) cells: effect of monensin intercalated into folatetagged liposomes. Eur J Pharm Sci. 2011; 43: 343-353.

9. Bozzuto, G., Molinari, A. Liposomes as nanomedical devices. Int J Nanomedicine. 2015;10:975-99.
10. Allen, T.M., Cullis, P.R. Liposomal drug delivery systems: from concept to clinical applications. Adv Drug Deliv Rev. 2013;65:36-48.

11. Gregoriadis, G., Florence, A.T. Liposomes in drug delivery. Clinical, diagnostic and ophthalmic potential. Drugs. 1993;45:15-28.

12. Pattni, B.S., Chupin, V.V., Torchilin, V.P. New Developments in Liposomal Drug Delivery. Chem Rev. 2015;a:A

13. Tiwari, E.A. Drug delivery systems: An updated review. International Journal of Pharmaceutical Investigation. 2012;2(1). Disponivel em: <www.jpionline.org>.

14. Coelho, J.F.P. Drug delivery systems: Advanced technologies potentially applicable in personalized treatments. EPMA Journal 2010;1(20):164-209.

15. Çağdaş, M., Sezer, A.D., Bucak, S. Liposomes as Potential Drug Carrier Systems for Drug. [S.l.]: [s.n.], 2014. Cap. 1, p. 1-50. Disponivel em: <https://www. intechopen.com/books/application-of-nanotechnologyin-drug-delivery/liposomes-as-potential-drug-carriersystems-for-drug-delivery>.

16. Usman, E.A. Niosomes: A Novel Trend of Drug Delivery. EJBPS European Journal of Biomedical. 2017;4,(7)17:436-42. Disponivel em: <http://www. ejbps.com>. SJIF Impact Factor 4.382.

17. More, E.A. Niosome: Comprehensive review. Asian Journal of Pharmaceutics. 2018;12(4).

18. Ge, X. et al. Advances of non-ionic surfactant vesicles (niosomes) and their application in drug delivery. Pharmaceutics. 2019;29(1). Disponivel em: <https:// www.mdpi.com/1999-4923/11/2/55/htm>. Acesso em: 19 Feb 2019. Impact Factor: 3.746.

19. Poste, G., Kirsh, R., Koestler, T. Liposomes and drug delivery in cancer chemotherapy. In: GREGORIADIS, G. Liposome Technology: targeted drug delivery and biological interation. [S.1.]: CRC Revivals. 2018;(3):21-3.

20. Agarwal V., Rani, R., Pandey, H. Liposome and their applications in cancer therapy. Braz. arch. biol. technol. 2016;59(8). dx.doi.org/10.1590/1678-43242016150477.

21. Federal Register. About: liposome drug products guidance for industryFDA. Website: Federal Register: The Daily Journal of the United States Government, 2018. Disponivel em: <https://www.federalregister.gov/ documents/2018/04/05/2018-06926/liposome-drugproducts-chemistry-manufacturing-and-controls-humanpharmacokinetics-and $>$. Acesso em: 10 fev. 2019.

22. Kazi, K.M. Niosome: A future of targeted drug delivery systems. Articles from Journal of Advanced Pharmaceutical Technology \& Research, 1, Oct-Dec 2010. 374-380. Disponivel em: <https://www.ncbi.nlm. nih.gov/pmc/articles/PMC3255404/>. Acesso em: 19 Feb 2019. 
23. Buffery, D. Innovation Tops Current Trends in the 2016 Oncology Drug Pipeline. American health \& drug benefit, 2016. Disponivel em: <ncbi.nlm.nih.gov>.

24. Institute for Healthcare Informatics. Global Medicines Use in 2020. IMS Institute. [S.1.]. 2015.

25. Henrya, L., Haysb, D.F. Cancer biomarkers. Molecular Oncology, 2012:140-6. Disponivel em: <www.elsevier. com/locate/molonc $>$.

26. Bulbake, U., et al. Liposomal Formulations in Clinical Use: An Updated Review. Pharmaceutics. 2017;2(27). Disponivel em: <https://www.ncbi.nlm.nih.gov/ pubmed/28346375>.

27. Lu, T. Formulation and optimization of idarubicin thermosensitive liposomes provides ultrafast triggered release at mild hyperthermia and improves tumor response. Journal of Controlled Release. 2015;(3): 42537. Disponivel em: <journal homepage: www.elsevier. com/locate/jconrel>.

28. Drug Development. About: Stimuvax - Investigational Therapeutic Cancer Vaccine. Drud Development Technology, 2019. Disponível em: <https://www. drugdevelopment-technology.com/projects/stimuvax/>. Acesso em: 18 fev. 2019.

29. Fiercebiotec. About: Oncothyreon routed after Merck KGaA's Stimuvax flops in PhIII lung cancer trial. Website:FierceBiotech.2012;19(December).Disponível em: $<$ https://www.fiercebiotech.com/r-d/oncothyreonrouted-after-merck-kgaa-s-stimuvax-flops-phiii-lungcancer-trial>. Acesso em: 18 fev. 19.

30. Wurz, G.T.E.A. Tecemotide: An antigen-specific cancer immunotherapy. Human Vaccines \& Immunotherapeutics. 2014;10(11):3383-93. Disponível em: $\quad<$ https://www.ncbi.nlm.nih.gov/pmc/articles/ PMC4514140/pdf/khvi-10-11-974454.pdf>.

31. Pfizer. About: Xalkori product. Xalkori ${ }^{\circledR}$ crizotinibe 2018 (10) Jul. Disponível em: <https://www.pfizer. com.br/sites/g/files/g10044511/f/product_attachments/ Xalkori_PS.pdf $>$. Acesso em: 20 Feb 2019.

32. Drug Development. About: Xalkori - Treatment for Non-Small Cell Lung Cancer. Drug development Technology, 2019. Disponivel em: <https://www. drugdevelopment-technology.com/projects/xalkori--treatment-for-nonsmall-cell-lung-cancer/>. Acesso em: 18 fev. 2019.
33. Drug Development Technology. Bayer and Orion report positive data from trial of darolutamide. Website: Drug Development Technology, 18 February 2019. Disponivel em: <https://www.drugdevelopment-technology.com/ news/bayer-orion-darolutamide-aramis-trial/>. Acesso em: 18 February 2019.

34. Sahu,A. Crizotinib: A comprehensive review. South Asian Journal of Cancer. 2013;(2):91-7. Disponível em: <https:// www.ncbi.nlm.nih.gov/pmc/articles/PMC3876666/>.

35. Broderick, J.M. About: Darolutamide Improves MFS in Phase III Nonmetastatic CRPC Trial. Websit: OncoLive, 24 Oct 2018. Disponível em: <https://www.onclive. $\mathrm{com} /$ web-exclusives/darolutamide-improves-mfs-inphase-iii-nonmetastatic-crpc-trial>.

36. Pharmaceutical Quality/CMC. Liposome Drug Products: Chemistry, Manufacturing, and Controls; Human Pharmacokinetics and Bioavailability; and Labeling Documentation. U.S. Department of Health and Human Services, Food and Drug Administration (FDA), Center for Drug Evaluation and Research (CDER). [S.1.]. 2018.

37. National Institutes of Health (NIH). PubChemDocs. About: PubChem. Disponível em: <https://pubchem. ncbi.nlm.nih.gov/>. Acesso em: 14 Feb 2019.

38. NHI U.S. National Library of Medicine. About the Company: DailyMed. WebSiteDailyMed, 2017. Disponivel em: <https://dailymed.nlm.nih.gov/ dailymed/>. Acesso em: 15 Feb 2019.

39. Research Solutions, TMIC. About: DruBank. Website: DrugBank, 20 Dec 2018. Disponível em: <https://www. drugbank.ca/>. Acesso em: 15 Feb 2019.

40. U.S. Food and Drug Administration; U.S. Department of Health and Human Services. Website: Us Food \& Drug Administration. About: Drug, fev. 2019. Disponivel em: $<$ https://www.accessdata.fda.gov/scripts/cder/ob/index. $\mathrm{cfm}>$. Acesso em: $11 \mathrm{Feb} 2019$.

41. Backman, H., Cao, Y., Girke, T. ChemMine tools: an online service for analyzing and clustering small molecules. Nucleic Acids Research. 2011;39(20):48691.

42. National Center for Biotechnology Information, NHI NationalHealthInstitute.About:OpenChemistryDatabase. WebSite: PubChem. Disponível em: <https://pubchem. ncbi.nlm.nih.gov/bioassay/1259409\#section=Top $>$. Acesso em: 20 Feb 2019. 


\title{
The Management of Electro-Medical Equipment in Intensive Care Units: Assurance of Traceability and Metrological Reliability
}

\author{
Juliana Lins de Oliveira*; Herman Augusto Lepikson \\ Centro Universitário SENAI CIMATEC; Salvador, Bahia, Brazil
}

\begin{abstract}
Physiological measurements in the health sector have been supported by the rapid evolution of medical equipment technologies. The health sector increasingly requires the development of mechanisms and applications that assure the metrological reliability of the results obtained using the equipment for the diagnosis, treatment, and monitoring of the clinical evolution of patients. This study demonstrates the weaknesses in the control of metrological parameters related to electro-medical equipment (EMS) in Brazil, specifically those used in Intensive Care Units (ICU), where reliability is critical in terms of survival, sequelae or death. We discuss essential determinants to ensure physiological measurements, such as the limitations of legislation/standards, laboratory infrastructure, voluntary accreditations, including a brief history and indicators of patient safety in Brazil and the United States of America, as well as data from research at Hospital Units (HUs) located in Salvador, Bahia, Brazil.
\end{abstract}

Keywords: Metrology. Health. Electro-Medical Equipment. Intensive Care Unit.

The basic principles of metrology are essential to several branches of technology because it is the science of measurement and its applications [1].

Recent advances in this science inside industrial environments have brought countless benefits related to measurement and operation reliability, traceability, quality, and safety. These are characteristics which are neither wellestablished nor present inside the Brazilian hospital environment.

The development of instruments has contributed to the manufacture of increasingly modern electro-medical equipment with the advances in science and technology since the XX century. This development has enabled biomedicine to measure several physiological parameters in isolated or parallel ways.

Essential signals, such as body temperature, heart or pulse rates, blood pressure, breathing frequency, and oxygen saturation are measured uninterruptedly and the results are necessary to diagnose disease, evaluate the patient's general

Received on 18 February 2019; revised 7 March 2019.

Address for correspondence: Dr. Juliana Lins. Centro Universitário SENAI CIMATEC. Avenida Orlando Gomes, N. 1845 - Piatã Zip code: 41650-010; Salvador, Bahia, Brazil. E-mail: julianalins@gmail.com.

J Bioeng. Biotech. Appl. Health 2019;2(2):70-74

(C) 2019 by SENAI CIMATEC. All rights reserved. clinical status, to observe response to therapy and can be used to help in rapid decision-making by professionals in Intensive Care Unit (ICU) or Emergence Room (ER). It is because these signals and other physiological measurements determine the basis of clinical problem solving [2]. Patients are more susceptible to hospital infections and adverse events (AE) in an ER.

An $\mathrm{AE}$ is a situation that occurs during the treatment that is not defined by the patient's clinical conditions. An AE is not an error, neglect or poor quality. It means an unwanted care result related to therapy or diagnosis. An AE attached to a mistake is an avoidable adverse event [3].

Research performed at Harvard Medical School concluded more than $20 \%$ of the ER patients suffered an avoidable AE [4]. Avoidable AEs are the ones of the most important consequences of the lack or inadequacy of metrological control of EEM. Therefore, there is a need for precise measurements and with the Unit International System (UIS) traceability. There is also need a law to control the metrological management of the EEM, laboratory infrastructure with accreditations to competent organizations and users capable of understanding the bad functioning or measurement error in equipment.

The risk of using equipment without accurate metrological evaluation increased emphasis after 1990 as a result of the Harvard Medical Practice 
Study publication, in which standards for the quantification of health services were established. They showed that from a total of 30,195 hospitalizations in the United States of America (USA), 1,133 AEs registered were preventable [5]. From there, the community began to devote greater attention to AEs. In 2000, the publication of the report "to err is human" by the Institute of Medicine (IoM) estimated that about 44,000 to 98,000 annual deaths in the United States of America (USA) were due to the failure of medical assistance. Approximately 1 million patients admitted to US hospitals a year were victims of AE assistance, more than half of them from mistakes that could have been prevented [6].

In 2002, the first world debate on the subject took place, sponsored by the World Health Organization (WHO) at the 55 $5^{\text {th }}$ World Health Assembly: "Quality of Care: Patient Safety"; then, in 2004, the "World Alliance for Patient Safety" was launched by WHO, of which Brazil was a signatory. In 2013, the National Patient Safety Program (NPSP, by Ordinance GM No. 529/MS) was created in Brazil and the resolution of the Collegiate Board (RDC No. 36) of the National Health Surveillance Agency (ANVISA-Brazil) introduced the obligatory core creation of NPSP in health establishments [7] with the goal of passing the record and treat the AEs. The chronology of the reference points regarding AEs in the world and Brazil is described in Figure 1.

The competent agencies, such as WHO, IoM and ANVISA have since been debating and developing legislation for patient safety and health care related
AEs. WHO estimates that one in every 10 patients suffers damage when receiving medical care in developed countries, and in developing countries, the number of events is higher [7].

In Brazil, despite the recording of AEs being compulsory since 2014 , the number of records in the NPSP corresponds to only $1.1 \%$ of the medical institutions in the country. In the period of 20142018, the country registered 205,290 occurrences of AEs, and the ERs in the HUs sector recorded the second highest number [8].

The metrological control of EEM used in ERs, with calibrations and tests traced to IS ensures not only the safety, reliability, and accuracy required by a sector of high complexity for the care of patients at risk or severe, but also a reduction in the occurrence of avoidable AEs.

\section{Aspects of Certification and Metrological Control of EEM in Brazil}

No product of interest to health, national or imported, can be industrialized, offered for sale or handed over to the Brazilian market before being registered in the Ministry of Health in Brazil (Law n ${ }^{\circ}$ 6,360/1976). Law $n^{\circ}$ 9,782/1999 gives ANVISA the responsibility of regulation, control, and inspection of the products and services that involve risk to public health. This includes the granting of product registration (Law $\mathrm{n}^{\circ}$ 9,782/1999) [9]. Resolution $n^{\circ}$ 444/August 1999 from ANVISA established the model adopted to ensure the safety of medical electrical equipment (model), adopting the technical standards of NBR

Figure 1. Chronology of reference frames for AEs.

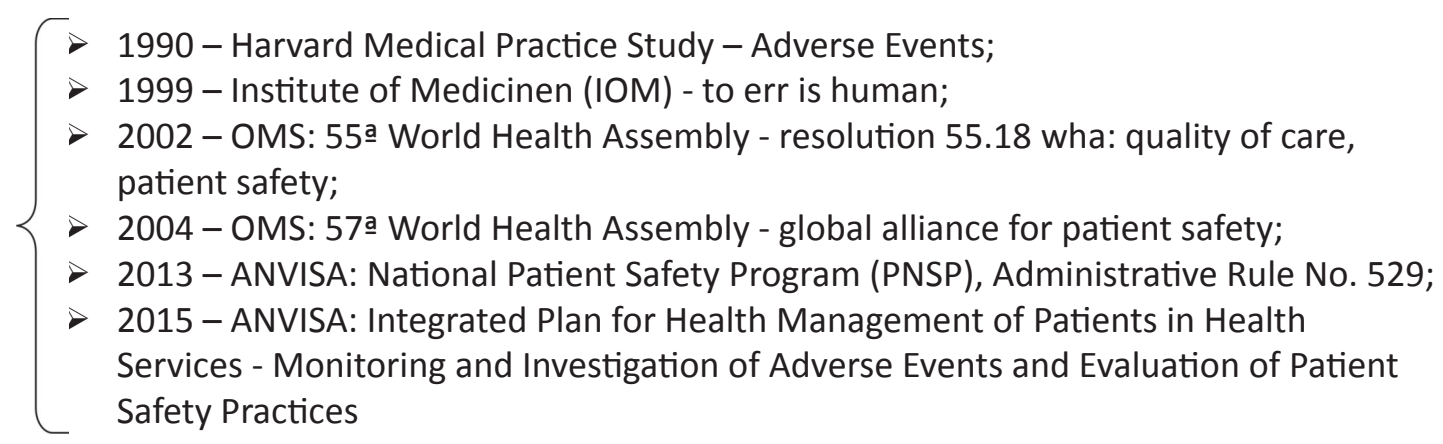


IEC 60,601 - 1 series: Electro-Medical Equipment. Part I - General Requirements for Safety; and Private Professional Standards -2. The compliance with the requirements established through the "good manufacturing practices for medical products" was determined for all suppliers of medical products by RDC 59/2000. The registry requirement from ANVISA grants certification of conformity to specific technical standards, issued by Certification Organizations for Products (COP) accredited by the National Institute of Metrology, Standardization and Industrial Quality (INMETRO-Brazil). The compliance results in the protection of the physical integrity of the users as well as the implementation of a good cycle between the regulator and productive systems [10].

The International Organization of Legal Metrology (IOLM) elaborates recommendations in which metrology is based on Technical Regulations for Measurement (TRM) prepared by INMETRO in Brazil. TRM puts several categories of measuring instruments, metrological and technical requirements for use and confirmation under central government control [11]. After delivery of any medical equipment to the customer, except for only clinical glass mercury thermometers, noninvasive mechanical aneroid sphygmomanometers and EEM used in the field of ionizing radiation, there is no law to regulate nor make compulsory metrological control tracing their performance over their life span. Currently, the only tool used in the direction of metrological reliability of EME in use is the voluntary accreditation of health establishments, which is conducted through national or international entities, including the International Standardization Organization (ISO), the National Accreditation Organization (NAO), the Joint Commission for Accreditation of Health Organizations (JCAHO), the American Association of Blood Banks (AABB). These entities are established agencies accredited to ensure the reliability of EEM, tracking calibrations as well as preventive and corrective maintenance [10].

According to the NationalSupplementary Health Agency (NSHA), by 2016, in Brazil, 133 hospitals had met important quality criteria as to the standard of care provided to the population. The data showed the performance of establishments according to three indicators: voluntary accreditation, hospital readmission, and patient safety. It was the first time that the NSHA offered information about the attributes of providers, helping consumers to monitor and evaluate the services received [12].

\section{About Survey}

The survey consisted of a literature review of theses, dissertations, and articles published in scientific meetings, journals, specialized journals, electronic consultation, analysis from ANVISA's reports and other relevant documents. There were also visits and questionnaires applied from May to July 2018 in UHs, of which two belong to SUS, and one is private, all located in Salvador, Bahia, Brazil. We searched for works that focus on the importance of metrology management of medical equipment of health, medical technology, metrology in health, adverse events in the hospital environment specifically in ERs, and legislation or specific standards.

\section{Results and Discussion}

There are 421 million hospitalizations annually and about 42.7 million AEs in the world. In the USA, these events are the third cause of death, reaching 400,000 deaths per year [13]. In 2002, a study in the United Kingdom showed that $28 \%$ of mercury sphygmomanometers and $42 \%$ of aneroides had errors of over $4 \mathrm{mmHg}$. The study also revealed that only one in every 54 physicians had taken the care to maintain and calibrate their sphygmomanometers [14]. INMETRO conducted a study of calibration verification of sphygmomanometers used in hospitals in Juiz de Fora, São Paulo, and Rio de Janeiro, in 1997. The results indicated that $61 \%$ of the checked sphygmomanometers had an error more significant than the maximum allowed, which is $4 \mathrm{~mm} \mathrm{Hg}$ [15]. In 2018, in Brazil, there were 321,321 health care establishments of different sizes [16] and only 3,401 SPs, which registered 205,290 AEs and 1,157 deaths/type of incidents from March/2014 
to May/2018. Bahia had 4,256 records. Of the total, 192,937 cases occurred in Hospital Unit (HUs), and 56,602 episodes occurred in UTIs [8] object of this study. A comparative study of three UHs was carried out in the city of Salvador, Bahia, one a member of a private network and two of the Unified Health System (SUS), all of them had ICUs, with 42.8 and 120 beds, respectively. None of them had a dedicated team for the metrological management of EEM, and only one had a member of staff with additional training in metrology. Two of them had regular maintenance and metrology management of EEM and intermediate checks in at least one hospital sector. Two had voluntary accreditation (ONA and QMENTUM) and only one registers AEs.

Brazil has 321,321 registered medical institutions and despite the compulsory creation of the NPSP, only 3,401 (1.1\%) take part in NPSP (1.1\%). This is taking into consideration that the NPSP provides unification in cases of several basic units in the same region. At best, with the unification of the number of establishments reduced to $50 \%$, the country should have approximately 161,000 NPSPs, which means that the real number of EAs in the country is far higher than what is known today. Despite the lack of reporting AEs, the ERs were the second type of service to register the highest rates over the last four years, accounting for $29.3 \%$ of incidents attributed to hospitals. If we assume that only $10 \%$ of these incidents are caused by failures or absence of metrological control of EEM, this would already indicate 5,660 incidents which could have been avoided. The survey also shows that no law or regulation makes the metrological control of EEM compulsory after commercialization in Brazil, nor any network of qualified laboratories and calibration service providers and tests that could meet the demand [10]. Furthermore, a set of actions that promote the further training in Metrology for users/ managers is necessary, EEM in the dissemination of metrology culture, HUs health metrology, indepth studies for the determination of uncertainty of measurement and other metrological parameters to promote error prevention in any sector.

\section{Acknowledgment}

To God, my family and my Prof. Dr. Herman A. Lepikson.

\section{References}

1. INMETRO. Vocabulário Internacional de Termos Fundamentais e Gerais de Metrologia - VIM, Portaria 029 de 1995, 3ª . Edição, 2012.Disponível em <http:// www.inmetro.gov.br/inovacao/publicacoes/vim_2012. pdf $>$, acessado em 15/05/2018.

2. Potter, P. Ann Fundamentos de enfermagem / Patricia A. Potter, Anne Griffi n Perry; [tradução de Maria Inês Corrêa Nascimento et al.]. - Rio de Janeiro: Elsevier, 2009. $7^{\mathrm{a}}$ ed. Pg 503.

3. Reason, J. Human error: models and management. BMJ. 2000;320(7237):768-70.

4. Mendes, W., Pavão, A.L.B., Martins, M., Moura, M.L.O., Travassos, C. 2013.

5. Brennan, T.A., Leape, L.L., Laird, N.M., et al. Incidence of adverse events and negligence in hospitalized patients: results of the Harvard Medical Practice Study I. N Engl J Med. 1991;324:370-6.

6. Kohn, L.T., Corrigan, J.M., Donaldson, M.S., et al. To err is human. Washington, DC: National Academy Press; 2000.

7. Caderno 7 ANVISA - Gestão de riscos e investigação de eventos adversos relacionados à assistência à saúde. Brasília, 2017.

8. Agência Nacional de Vigilância Sanitária. Relatório dos Estados, Eventos Adversos. Disponível em: https:// www20.anvisa.gov.br/segurancadopaciente/index.php/ publicacoes/category/relatorios-dos-estados $>$ Acesso em 26 de jun.2018.

9. Manual de Regularização de Equipamentos Médicos na ANVISA, 2017, disponível em<http://portal.anvisa. gov.br/documents/33912/264673/Manual+para+regul ariza $\% \mathrm{C} 3 \% \mathrm{~A} 7 \% \mathrm{C} 3 \% \mathrm{~A} 3 \mathrm{o}+\mathrm{de}+$ equipamentos $+\mathrm{m} \% \mathrm{C} 3$ $\%$ A9dicos+na+Anvisa/ > acessado em 18 de julho de 2018.

10. Monteiro, E.C., Lessa, M.L.Ametrologia na área da saúde: garantia da segurança e da qualidade dos equipamentos eletromédicos. Pontifícia Universidade Católica do Rio de Janeiro - Programa de Pós-Graduação em Metrologia (Pós-MQI). Engevista 2005:52.Disponível em <http:// www.uff.br/engevista/2_7Engevista05.pdf.> Acessado em 15/05/2018.

11. Menezes, C.I.C., Salles, M.T., Silva, M.A.S. Uma Ferramenta para melhoria da Qualidade dos Instrumentos da Área da Saúde. Metrologia-2003 - Metrologia para a Vida Sociedade Brasileira de Metrologia (SBM). 2003:1-7. 
12. Lista de hospitais com acreditação máxima, disponível em<http://www.ans.gov.br/aans/noticias-ans/qualidade-dasaude/3245-ans-divulga-lista-de-hospitais-que-atendemcriterios-de-qualidade>, acessado em 20/07/2018.

13. Makary, M.A., Daniel, M. Medical error - the third leading cause of death in the US. BMJ. 2016;2139(353):1-5.

14. Waugh, J.J., et al. Hidden errors of aneroid sphygmomanometers. Blood Press Monit 2002;7:309-12.
15. Instituto Nacional de Metrologia, Normalização e Qualidade Industrial. Esfigmomanômetros. Disponível em <http://www.inmetro.gov.br/ consumidor/produtos/esfigmo.asp $>$.Acesso em 17 de ag. 2018.

16. Datasus. Disponível em: <http://cnes2.datasus.gov. br/Mod_Ind_Unidade.asp? VEstado $=00>$ Acesso em 20 de jun. 2018 . 


\title{
Osteoma: A Case Report Based on Image Technology
}

\begin{abstract}
Alile Carmo ${ }^{1 *}$; Ana Carolina Mariz² ; Leandro Santos ${ }^{3}$; Marianna Torres ${ }^{4}$; Raí Santos ${ }^{5}$; Roberto Monteiro ${ }^{6}$ ${ }^{1}$ University Center CIMATEC, Department of Computational Modeling and Industrial Technology; ${ }^{2}$ Ana Carolina Ramos Mariz, Federal University of Bahia, Institute of Health, Dentistry Department, ${ }^{3}$ Leandro Brito Santos, State University of Bahia; ${ }^{4}$ Marianna Torres, Federal University of Bahia, Institute of Health, Dentistry Department; ${ }^{5}$ Rai Faustino Miranda Santos, University Center CIMATEC, Department of Computational Modeling and Industrial Technology; ${ }^{6}$ Roberto Luiz Souza Monteiro, University Center CIMATEC, Department of Computational Modeling and Industrial Technology; Salvador, Bahia, Brazil
\end{abstract}

\begin{abstract}
Osteomas are benign mesenchymal tumors, characterized by proliferation of compact or modularly bone. They are small, slow-growing lesions, usually asymptomatic and detected in young adults. This tumors can affect the paranasal sinuses and are often diagnosed with incidental findings through imaging tests. Osteomas are typically restricted to the craniofacial skeleton and rarely found in other bones. Osteoma of the gnathic bones may be peripheral or endosteal. The osteomas' etiology is controversial and still unknown. It is more frequent in the frontal sinuses, corresponding to $57 \%$ of the paranasal sinuses osteomas, followed by the ethmoidal and maxillary sinuses. Computed Tomography (CT) is the gold standard to assess the location, extent, and aspects of the injury. The objective of this paper is to present a case report of osteoma diagnosed by computed tomography (CT) scan, indicating the importance of the technology of imaging in the medicine diagnostic.
\end{abstract}

Keywords: Osteoma. Paranasal Sinus Osteomas. Frontal Sinus Osteoma. Computed Tomography.

Osteomas of the frontal sinus is uncommon but not rare [1-8]. Recent surveys confirm that the frontal sinus is the most common location of this benign neoplasms [7]. Osteomas are the most common benign tumors that arise in the paranasal sinuses and the nose, with a slow-growing rate, well-circumscribed, indolent lesions that develop predominantly into the frontal sinus $(80 \%$ of the sinus localization) [6-8]. In the beginning, small osteomas are usually asymptomatic $[3,4,6-8]$. The clinical symptoms depend on the location and the size of the tumor [6]. The most common symptom is a frontal headache or facial pain. Osteomas are usually identified accidentally by X-Ray or CT scan images [6]. The cause of frontal sinus osteoma is unknown and speculative. Many theories have been proposed, but it is uncertain [3-8].

From the histological point of view, there are three types of sinus osteomas [2-8]:

1. Eburnated (ivory, compact type) - very dense, with no evidence of Haversian canals;

Received on 20 February 2019; revised 4 March 2019.

Address for correspondence: Dr. Alile Fixina do Carmo. Avenida $60 \mathrm{Dr}^{\circ}$ Antonio Monteiro Street, Apt. \# 502, Zip Code: 41815-130, Salvador, Bahia, Brazil, phone: +55 71 988960093; e-mail: afcarmo76@gmail.com.

J Bioeng. Biotech. Appl. Health 2019;2(2):75-77.

C 2019 by SENAI CIMATEC. All rights reserved.
2. Mature, spongious osteomas - osseous trabecules associated with fibrous tissue and collagen fibers;

3. Mixed types - with both (1 and 2) histological types.

Two main protocols are used in these tumors: 1. Conservatory: if the osteoma is small and asymptomatic, the better perform is to wait and check the progression of the neoplasm; and 2 . Surgical treatment: if the osteoma has rapidgrowth, presence of infections, severe pain, or orbital complications because of the tumor extension, the surgery is the best procedure [6].

A 37-year-old right-handed female was attended in the clinic of diagnostic imaging at Camaçari city (Bahia, Brazil) to evaluate the maxillary sinuses. During the analysis of the sinus X-ray of the face, a clear radiopaque image was found, located near the upper middle contour of the right orbit, ethmoidal sinus and inferior contour of the frontal sinus (Figure 1). The computed tomography (CT) confirmed the osteoma in the region (Figure 2). Based on the patient clinical history, radiographic images, and histopathology of the lesion, the treatment chosen was conservative.

Osteoma can be observed in any age group, being more prevalent in the third and fourth 
Figure 1. The sinus X-ray of the face.

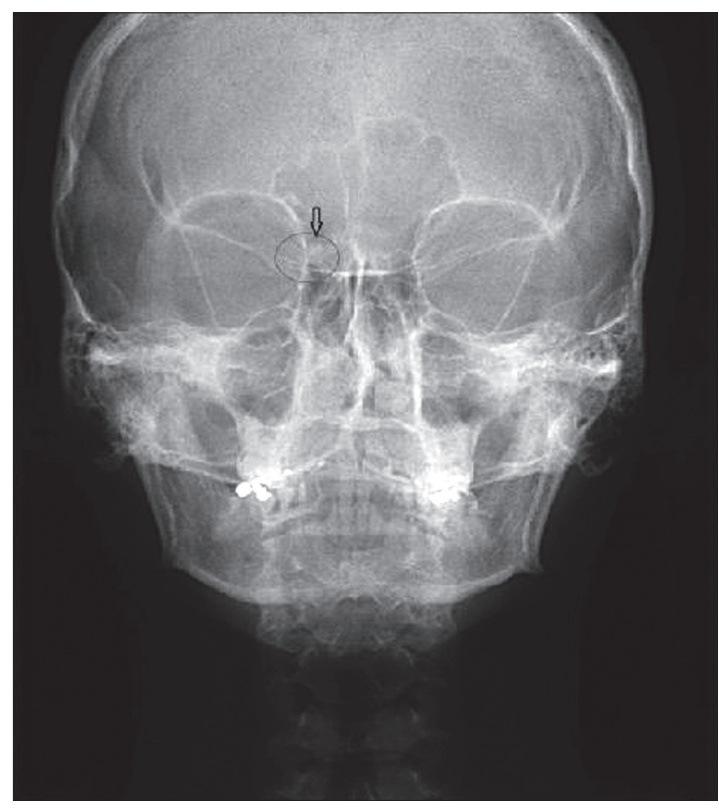

Figure 2. Osteoma visualized on computed tomography (CT).

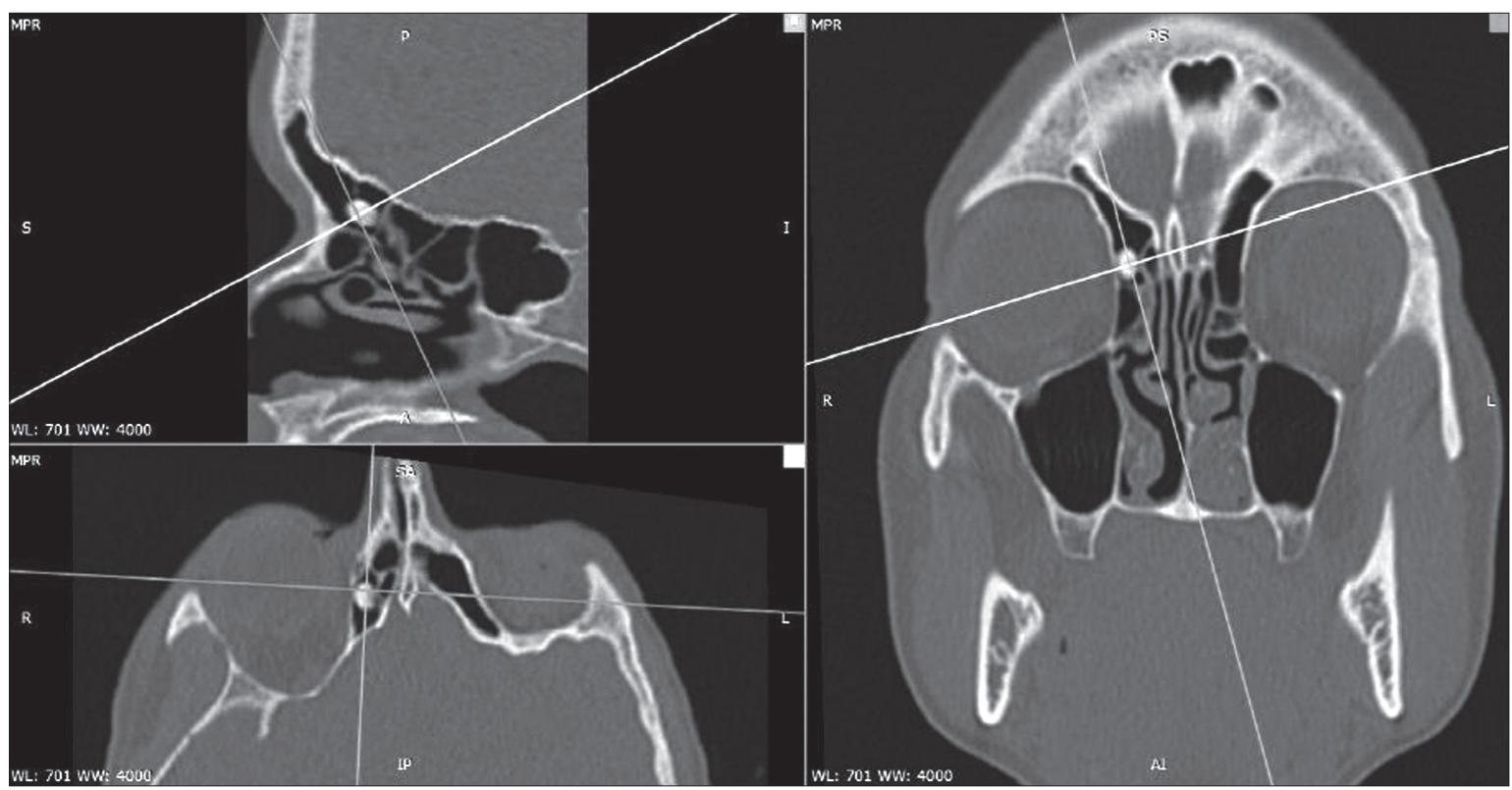

decades of life. The etiology of the osteomas is unknown, in which many theories could be admitted, such as trauma, embryology, infectious diseases, and genetic. Osteomas are benign, indolent, slow-growing tumors of the skull and facial bones, commonly arising around the paranasal sinuses. In about $80 \%$ of cases, they are found solely within the frontal sinus, however the ethmoidal, maxillary, and rarely sphenoid sinuses might be affected as well. The osteoma cannot be considered as the causative agent of the headache, but could be regarded as the complaint that led to 
complementary radiological examination, such as CT.

Diagnosis of osteomas is frequently made incidentally in X-rays, but more especifically with the technology of computed tomography scans. Therefore, the careful evaluation of the radiologist is essential to identify osteomas due to their small size, because they may go unnoticed.

\section{Acknowledgements}

We would like to thank CIMATEC, Federal University of Bahia (UFBA) and CEBRO Clinic for all support in the development of this study.

\section{References}

1. Alsebeith, K.; Desrosiers, M. Bifrontal endoscopic resection of frontal sinus osteoma. The Laryngoscope. 1998;108(2):295-8.
2. Canella, C. Ostenoid osteoma: diagnosis and treatment. Radiologia Brasileira. 2015;48(4):v-v. http://dx.doi. org/10.1590/0100-3984.2015.48.4e1.

3. Fobe, L.P.O; Melo, E.C.; Canone, L.F. Fobe, JL. Cirurgia de osteoma de seio frontal. Arq Neuropsiquiatr, 2002;60(1):101-5.

4. Licci, M. et al. Frontoethmoidal osteoma with secondary intradural mucocele extension causing fronal lobe syndrome and pneumocephalus: Case report and literature review. World Neurosurgery. 2018;115:301-8. https://doi.org/10.1016/j.wneu.2018.04.071.

5. Pons, Y. et al. Ethmoid sinus osteoma: diagnosis and management. Head \& Neck, 2013;35(2):201-4. doi: 10.1002/hed.22945.

6. Sarafoleanu, C; Decusara, R.E. Frontal sinus osteoma. Romanian Journal of Rhinology. 2016;6(22):113-14.

7. Smith, M.E.; Calcaterra, T.C. Frontal sinus osteoma. Annals of Otology, Rhinology \& Laryngology. 1989;98(11):896-900.

8. Summers, L.E. et al. Frontal sinus osteoma associated with cerebral abscess formation: A case report. Surgical Neurology. 2001;55(4):235-9. 


\section{Instructions for Authors}

The Authors must indicate in a cover letter the address, telephone number and e-mail of the corresponding author. The corresponding author will be asked to make a statement confirming that the content of the manuscript represents the views of the co-authors, that neither the corresponding author nor the co-authors have submitted duplicate or overlapping manuscripts elsewhere, and that the items indicated as personal communications in the text are supported by the referenced person. Also, the protocol letter with the number should be included in the submission article, as well as the name of sponsors (if applicable).

Manuscripts may be submitted within designated categories of communication, including:

- Original basic or clinical investigation (original articles on topics of broad interest in the field of bioengineering and biotechnology applied to health). We particularly welcome papers that discuss epidemiological aspects of international health, clinical reports, clinical trials and reports of laboratory investigations.

- Case presentation and discussion (case reports must be carefully documented and must be of importance because they illustrate or describe unusual features or have important practice implications).

- Brief reports of new methods or observations (short communications brief reports of unusual or preliminary findings).
- State-of-the-art presentations (reviews on protocols of importance to readers in diverse geographic areas. These should be comprehensive and fully referenced).

- Review articles (reviews on topics of importance with a new approach in the discussion). However, review articles only will be accepted after an invitation of the Editors.

- Letters to the editor or editorials concerning previous publications (correspondence relating to papers recently published in the Journal, or containing brief reports of unusual or preliminary findings).

- Editor's corner, containing ideas, hypotheses and comments (papers that advance a hypothesis or represent an opinion relating to a topic of current interest).

- Innovative medical products (description of new biotechnology and innovative products applied to health).

- Health innovation initiatives articles (innovative articles of technological production in Brazil and worldwide, national policies and directives related to technology applied to health in our country and abroad).

The authors should checklist comparing the text with the template of the Journal.

Supplements to the JBTH include articles under a unifying theme, such as those summarizing presentations of symposia or focusing on a specific subject. These will be added to the regular publication of the Journal as appropriate, and will be peer reviewed in the same manner as submitted manuscripts.

\section{Statement of Editorial Policy}

The editors of the Journal reserve the right to edit manuscripts for clarity, grammar and style. Authors will have an opportunity to review these changes prior to creation of galley proofs. Changes in content after galley proofs will be sent for reviewing and could be required charges to the author. The JBTH does not accept articles which duplicate or overlap publications elsewhere.

\section{Peer-Review Process}

All manuscripts are assigned to an Associate Editor by the Editor-in-Chief and Deputy
Editor, and sent to outside experts for peer review. The Associate Editor, aided by the reviewers' comments, makes a recommendation to the Editor-in-Chief regarding the merits of the manuscript. The Editor-in-Chief makes a final decision to accept, reject, or request revision of the manuscript. A request for revision does not guarantee ultimate acceptance of the revised manuscript.

Manuscripts may also be sent out for statistical review ou ad hoc reviewers. The average time from submission to first decision is three weeks. 
$\underline{\text { Revisions }}$

Manuscripts that are sent back to authors for revision must be returned to the editorial office by 15 days after the date of the revision request. Unless the decision letter specifically indicates otherwise, it is important not to increase the text length of the manuscript in responding to the comments. The cover letter must include a point-by-point response to the reviewers and Editors comments, and should indicate any additional changes made. Any alteration in authorship, including a change in order of authors, must be agreed upon by all authors, and a statement signed by all authors must be submitted to the editorial office.

\section{Style}

Manuscripts may be submitted only in electronic form by www.jbthonline.com. Each manuscript will be assigned a registration number, and the author notified that the manuscript is complete and appropriate to begin the review process. The submission file is in OpenOffice, Microsoft Word, or RTF document file format for texts and JPG (300dpi) for figures.

Authors must indicate in a cover letter the address, telephone number, fax number, and e-mail of the corresponding author. The corresponding author will be asked to make a statement confirming that the content of the manuscript represents the views of the co-authors, that neither the corresponding author nor the co-authors have submitted duplicate or overlapping manuscripts elsewhere, and that the items indicated as personal communications in the text are supported by the referenced person.

Manuscripts are to be typed as indicated in Guide for Authors, as well as text, tables, references, legends. All pages are to be numbered with the order of presentation as follows: title page, abstract, text, acknowledgements, references, tables, figure legends and figures. A running title of not more than 40 characters should be at the top of each page. References should be listed consecutively in the text and recorded as follows in the reference list, and must follow the format of the National Library of Medicine as in Index Medicus and "'Uniform Requirements for Manuscripts Submitted to Biomedical Journals" or in "Vancouver Citation Style". Titles of journals not listed in Index Medicus should be spelled out in full.

Manuscript style will follow accepted standards. Please refer to the JBTH for guidance. The final style will be determined by the Editor-in-Chief as reviewed and accepted by the manuscript's corresponding author.

\section{Approval of the Ethics Committee}

The JBTH will only accept articles that are approved by the ethics committees of the respective institutions (protocol number and/or approval certification should be sent after the references). The protocol number should be included in the end of the Introduction section of the article.

\section{Publication Ethics}

Authors should observe high standards with respect to publication ethics as set out by the International Committee of Medical Journal Editors (ICMJE). Falsification or fabrication of data, plagiarism, including duplicate publication of the authors' own work without proper citation, and misappropriation of the work are all unacceptable practices. Any cases of ethical misconduct are treated very seriously and will be dealt with in accordance with the JBTH guidelines.

\section{Conflicts of Interest}

At the point of submission, each author should reveal any financial interests or connections, direct or indirect, or other situations that might raise the question of bias in the work reported or the conclusions, implications, or opinions stated - including pertinent commercial or other sources of funding for the individual author(s) or for the associated department(s) or organizations(s), and personal relationships. There is a potential conflict of interest when anyone involved in the publication process has a financial or other beneficial interest in 
the products or concepts mentioned in a submitted manuscript or in competing products that might bias his or her judgment.

\section{Material Disclaimer}

The opinions expressed in JBTH are those of the authors and contributors, and do not necessarily reflect those of the ITS/SENAI CIMATEC, the editors, the editorial board, or the organization with which the authors are affiliated.

\section{Privacy Statement}

The names and email addresses entered in this Journal site will be used exclusively for the stated purposes of this journal and will not be made available for any other purpose or to any other party.

\section{Brief Policies of Style}

\begin{tabular}{|c|c|c|c|c|c|c|c|c|}
\hline Manuscript & Original & Review & $\begin{array}{c}\text { Birief } \\
\text { Comunication }\end{array}$ & Case Report & $\begin{array}{l}\text { Editorial ; Letter } \\
\text { to the Editor; } \\
\text { Editor's Corner }\end{array}$ & $\begin{array}{l}\text { Innovative } \\
\text { Medical } \\
\text { Products }\end{array}$ & State-of-the-Art & $\begin{array}{c}\text { Health } \\
\text { Innovation } \\
\text { Initiatives }\end{array}$ \\
\hline Font Type & Times or Arial & Times or Arial & Times or Arial & Times or Arial & Times or Arial & Times or Arial & Times or Arial & Times or Arial \\
\hline $\begin{array}{l}\text { Number of Words } \\
\text { - Title }\end{array}$ & 120 & 90 & 95 & 85 & 70 & 60 & 120 & 90 \\
\hline $\begin{array}{l}\text { Font Size/Space- } \\
\text { Title }\end{array}$ & 12; double space & 12; double space & 12; double space & 12; double space & 12; double space & 12; double space & 12; double space & 12; double space \\
\hline $\begin{array}{l}\text { Font Size/Space- } \\
\text { Abstracts/Key } \\
\text { Words and } \\
\text { Abbreviations }\end{array}$ & 10; single space & 10 ; single space & 10; single space & 10; single space & - & - & 10; single space & 10; single space \\
\hline $\begin{array}{l}\text { Number of Words } \\
\text { - Abstracts/Key } \\
\text { Words }\end{array}$ & $300 / 5$ & $300 / 5$ & $200 / 5$ & $250 / 5$ & - & - & $300 / 5$ & $300 / 5$ \\
\hline $\begin{array}{l}\text { Font Size/Space- } \\
\text { Text }\end{array}$ & 12; Double space & 12; Double space & 12; Double space & 12; Double space & 12; Double space & 12; Double space & 12; Double space & 12; Double space \\
\hline $\begin{array}{l}\text { Number of Words } \\
- \text { Text }\end{array}$ & $\begin{array}{l}5,000 \text { including } \\
\text { spaces }\end{array}$ & $\begin{array}{l}5,500 \text { including } \\
\text { spaces }\end{array}$ & $\begin{array}{l}2,500 \text { including } \\
\text { spaces }\end{array}$ & $\begin{array}{l}1,000 \text { including } \\
\text { spaces }\end{array}$ & $\begin{array}{l}1,000 \text { including } \\
\text { spaces }\end{array}$ & $\begin{array}{l}550 \text { including } \\
\text { spaces }\end{array}$ & $\begin{array}{l}5,000 \text { including } \\
\text { spaces }\end{array}$ & $\begin{array}{l}5,500 \text { including } \\
\text { spaces }\end{array}$ \\
\hline $\begin{array}{l}\text { Number of } \\
\text { Figures }\end{array}$ & $\begin{array}{c}8 \text { (title font size } \\
12 \text {, double space) }\end{array}$ & $\begin{array}{c}3 \text { (title font size } \\
12 \text {, double space) }\end{array}$ & $\begin{array}{c}2 \text { (title font size } \\
12, \text { double space) }\end{array}$ & $\begin{array}{c}2 \text { (title font size } \\
12, \text { double space) }\end{array}$ & - & $\begin{array}{c}2 \text { (title font size } \\
12, \text { double space) }\end{array}$ & $\begin{array}{c}8 \text { (title font size } \\
12 \text {, double space) }\end{array}$ & $\begin{array}{c}8 \text { (title font size } \\
12 \text {, double space) }\end{array}$ \\
\hline $\begin{array}{l}\text { Number of } \\
\text { Tables/Graphic }\end{array}$ & $\begin{array}{c}7 \text { title font size } 12, \\
\text { double space }\end{array}$ & $\begin{array}{c}2 \text { title font size } 12, \\
\text { double space }\end{array}$ & $\begin{array}{c}\text { 2(title font size } 12 \\
\text { double space) }\end{array}$ & $\begin{array}{c}\text { 1(title font size } 12, \\
\text { double space) }\end{array}$ & - & - & $\begin{array}{c}7 \text { title font size } 12, \\
\text { double space }\end{array}$ & $\begin{array}{c}4 \text { title font size } 12, \\
\text { double space }\end{array}$ \\
\hline $\begin{array}{l}\text { Number of } \\
\text { Authors and Co- } \\
\text { authors }{ }^{*}\end{array}$ & 15 & 10 & 5 & 10 & 3 & 3 & 15 & 10 \\
\hline References & $\begin{array}{c}20 \text { (font size } \\
10, \text { single space }\end{array}$ & $\begin{array}{c}30 \text { (font size } \\
10 \text {,single space }\end{array}$ & $\begin{array}{c}15 \text { (font size } \\
10, \text { single space) }\end{array}$ & $\begin{array}{c}10 \text { (font size } \\
10, \text { single space) }\end{array}$ & $\begin{array}{c}10 \text { (font size } \\
10, \text { single space }\end{array}$ & $\begin{array}{c}5 \text { (font size } \\
10, \text { single space }\end{array}$ & $\begin{array}{c}20 \text { (font size } \\
10, \text { single space }\end{array}$ & 20 \\
\hline
\end{tabular}

*First and last name with a sequencing overwritten number. Corresponding author(s) should be identified with an asterisk; Type 10, Times or Arial, single space. Running title of not more than 40 characters should be at the top of each page. References should be listed consecutively in the text. References must be cited on (not above) the line of text and in brackets instead of parentheses, e.g., [7,8]. References must be numbered in the order in which they appear in the text. References not cited in the text cannot appear in the reference section. References only or first cited in a table or figures are numbered according to where the table or figure is cited in the text. For instance, if a table is placed after reference 8 , a new reference cited in table 1 would be reference 9.1 would be reference 9 . 


\section{Checklist for Submitted Manuscripts}

$\square$ 1. Please provide a cover letter with your submission specifying the corresponding author as well as an address, telephone number and e-mail.

2. Submit your paper using our website www.jbthonline.com. Use Word Perfect/Word for Windows, each with a complete set of original illustrations.

口3. The entire manuscript (including tables and references) must be typed according to the guidelines instructions.

4. The order of appearance of material in all manuscripts should be as follows: title page, abstract, text, acknowledgements, references, tables, figures/graphics/diagrams with the respective legends.

口5. The title page must include a title of not more than three printed lines (please check the guidelines of each specific manuscript), authors (no titles or degrees), institutional affiliations, a running headline of not more than 40 letters with spaces.

口6. Acknowledgements of persons who assisted the authors should be included on the page preceding the references.

7. References must begin on a separate page.

$\square$ 8. References must be cited on (not above) the line of text and in brackets instead of parentheses, e.g., $[7,8]$.

口9. References must be numbered in the order in which they appear in the text. References not cited in the text cannot appear in the reference section. References only or first cited in a table or figures are numbered according to where the table or figure is cited in the text. For instance, if a table is placed after reference 8 , a new reference cited in table 1 would be reference 9.

10. Reference citations must follow the format established by the "Uniform Requirements for Manuscripts Submitted to Biomedical Journals" or in "Vancouver Citation Style".

11. If you reference your own unpublished work (i.e., an "in press" article) in the manuscript that you are submitting, you must attach a file of the "in press" article and an acceptance letter from the journal.

12. If you cite unpublished data that are not your own, you must provide a letter of permission from the author of that publication.

13. Please provide each figure in high quality (minimum 300 dpi: JPG or TIF). Figure must be on a separate file.

14. If the study received a financial support, the name of the sponsors must be included in the cover letter and in the text, after the author's affiliations.

15. Provide the number of the Ethics Committees (please check the guidelines for authors). 
